\title{
Viscous Models Comparison in Water Impact of Twin 2D Falling Wedges Simulation by Different Numerical Solvers
}

\author{
Mehdi Mahmoodi $^{1 *}$, Roya Shademani ${ }^{2}$, Mofid Gorji Bandpy ${ }^{3}$ \\ ${ }^{1}$ Ph.D. Student, Babol Noshirvani University of Technology; mehdymahmoody@gmail.com \\ ${ }^{2}$ Ph.D. Student, Amirkabir University of Technology; r_shademani@aut.ac.ir \\ ${ }^{3}$ Professor; Babol Noshirvani University of Technology; gorji@nit.ac.ir
}

\section{ARTICLE INFO}

\section{Article History:}

Received: 17 Mar. 2017

Accepted: 9 Nov. 2017

Keywords:

Falling Wedges

Two Phases

Phase Field

Volume of Fluid

Dynamic Mesh

\begin{abstract}
In this paper, symmetric water entry of twin wedges is investigated for deadrise angle of 30 degree. Three numerical simulation of a symmetric impact, considering rigid body dynamic equations of motion in two-phase flow is presented. The two-phase flow around the wedges is solved by Finite Element based on Finite Volume method (FEM-FVM) which is used in conjunction with Volume of Fluid (VOF) scheme in ANSYS Fluent and ANSYS CFX and Phase Field scheme in COMSOL Multiphysics. The method and scheme of simulation are validated by experimental data for geometry with one wedge. The dynamic mesh, mesh motion and moving mesh models are used to simulate dynamic motion of the wedges in ANSYS Fluent, ANSYS CFX and COMSOL Multiphysics, respectively. The vertical velocity and pressure coefficient versus time are determined and comparisons of the computed mentioned parameters against experimental data are performed. The eight characteristics effects of fluid flow are investigated till 0.25 second after wedges falling including impact event. It is demonstrated that the ANSYS Fluent and k- $\varepsilon$ were the best software and viscous model, respectively.
\end{abstract}

\section{Introduction}

Fluid-solid impact problems associated with water entry have important applications in various aspects of ocean engineering and naval architecture. The impact phenomenon usually occurs in a short time, while the force and momentum can be exceedingly large and hazardous for various structures. The most popular shape of high speed crafts keel is wedge shape. For the constant speed water-entry problems, the flow becomes self-similar, when the effects of gravity and viscosity are ignored. This means that the flow patterns at different instances is the same [1]. Von Karman [2] and Wagner [3] were studied the impact problem by wedges and circular cylinders. Several theoretical and numerical methods have been proposed to solve more general two dimensional water-entry problems. To indicate a few, these include similarity flow solutions for wedges by Shademani and Ghadimi [4] or Ghazizade and Nikseresht [5], matched asymptotic expansions by Armand and Cointe [6], nonlinear numerical methods by Greenhow [7] or Farsi and Ghadimi [8 and 9] or Yamada et al. [10] or Luo et al. [11], conformal mapping methods by Ghadimi et al. [12] or Shah et al.
[13] and CFD techniques by Panahi [14] or Panciroli [15] or Piro and Maki [16]. It is difficult to obtain a fully nonlinear solution of the water-entry impact problem even in the regime of the potential flow theory. The difficulties are mainly due to the local jet flow with high velocities near the free surface intersection and gravity effect. Zhao and Faltinsen [17] presented a two dimensional nonlinear boundary element solution without gravity. A jet flow is created at the intersection between the free surface and the body surface. So they decided to neglect this part of the jet, where the pressure is close to atmospheric pressure. Booki and Yung [18] proposed a simplified method that adopts the equipotential free surface condition for practical calculations. To fully analyze the impact forces and the environment resulting structural responses, various phenomena like compressibility effect, free surface deformation, flow regime, wetted surface of the body, trapped air, and the separation of the fluid on the body surface must be modeled properly.

In this study, the symmetric impact of two dimensional wedges in two-phase flow is numerically simulated with coupling the rigid body dynamic 
equations of motion. The gravity effect was applied. Turbulent two-phase flow is solved based on the finite volume method and the interface is tracked with the volume of fluid (VOF) scheme in ANSYS Fluent and ANSYS CFX and the phase field scheme in COMSOL Multiphysics. Dynamic equations and a dynamic mesh (or named mesh motion in ANSYS CFX or named moving mesh in COMSOL Multiphysics) are used to obtain the real velocity distribution during a symmetric impact. The physical parameters such as pressure coefficient, drag coefficient, total pressure (stagnation pressure), dynamic pressure, vertical velocity, vorticity, drag force, $\mathrm{Z} / \mathrm{D}$ ratio and turbulence intensity in this study are investigated for two wedges simulation till 0.25 second after falling. Different viscous models such as $\mathrm{k}-\varepsilon, \quad \mathrm{k}-\mathrm{w}, \quad$ Reynolds stress and shear stress transportation (SST) versus laminar by three different numerical solver package called ANSYS Fluent, ANSYS CFX and COMSOL Multiphysics were implemented. In the following section, the governing equations are discussed, followed by validation of numerical method and the results and discussion.

\section{Governing Equations}

The continuity and momentum equations are as follow:

$\partial u_{i} / \partial x_{i}=0$

$\frac{\partial u_{j}}{\partial t}+\frac{\partial u_{i} u_{j}}{\partial x_{i}}=-\frac{1}{\rho} \frac{\partial P}{\partial x_{j}}+g_{j}+F_{j} / \rho+$

$+\frac{\partial}{\partial x_{i}}\left[\frac{\mu+\mu_{t}}{\rho}\left(\frac{\partial u_{i}}{\partial x_{j}}+\frac{\partial u_{j}}{\partial x_{i}}\right)\right]$

Note that the dynamic condition, i.e., continuity of pressure at the interface is automatically implemented. The kinematic condition, which states that the interface is convected with the fluid, can be expressed in terms of volume fraction $\varphi$ as follow:

$$
D \varphi / D t=\partial_{t} \varphi+(\vec{V} \cdot \vec{\nabla}) \varphi=0
$$

In the VOF method the interface is described implicitly. The data structure that represents the interface is the fraction $\varphi$ of each cell that is filled with a reference phase, say phase 1 . The scalar field $\varphi$ is often referred to as the color function. The magnitude of $\varphi$ in the cells cut by the free surface is between 0 and $1(0<\varphi<1)$ and away from it, is either zero or one. The $\mu$ and $\rho$ at any cell (denoted by $i, j$ ) can be computed using a simple volume average over the cell:

$$
\begin{aligned}
& \rho_{i j}=\varphi_{i j} \rho_{l}+\left(1-\varphi_{i j}\right) \rho_{a} \\
& \mu_{i j}=\varphi_{i j} \mu_{l}+\left(1-\varphi_{i j}\right) \mu_{a}
\end{aligned}
$$

where subscripts (l) and (a) denote liquid and air respectively. The PISO procedure has been used for the velocity pressure coupling. Furthermore, the second order upwind scheme has been applied to discrete momentum, turbulent kinetic energy and turbulence dissipation rate equations. In the rigid body motion with three degrees of freedom, the pressure and shear stress are used to determine aerodynamic and hydrodynamic forces and moments acting on the rigid body. These forces and moments, in turn, accompanied by external forces and moments are used in general solution of motion, to obtain linear and angular displacement of a rigid body. The equations of rigid body motion with constant mass and moments of inertia are solved to determine translational and angular velocity and also displacement at each time step. These equations are as follows:

$\sum \vec{F}=m(d \vec{v} / d t)$

$\sum \vec{M}=\vec{I} \vec{\alpha}$

Parameters in turbulence models were used the same as pre-assumed constant of soft-wares.

\section{Validation}

At first, the symmetric water impact of a twodimensional wedge has been simulated and the results are compared with the experimental data of Zhao et al. [19]. The definition of parameters and the geometry of the validation problem are described in Figure 1.

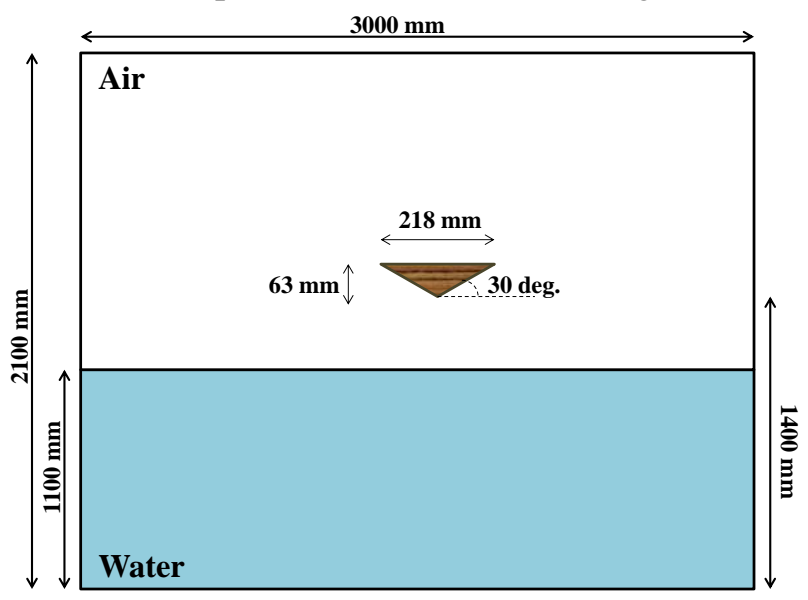

Figure 1. Geometrical configuration of the experimental data.

The body mass of wedge is 241 kilogram and its initial velocity is 5.5 meter per second. The wedge is fallen from a specified initial altitude with this initial velocity, and due to the gravitational forces its velocity increases until water impact happens. Shortly after the water impact, the velocity of the wedge 
decreases due to the slamming force exerted on the wedge by the water. The results of ANSYS Fluent are closest values to the experimental data versus other two softwares as shown in Figure 2 and Figure 3.

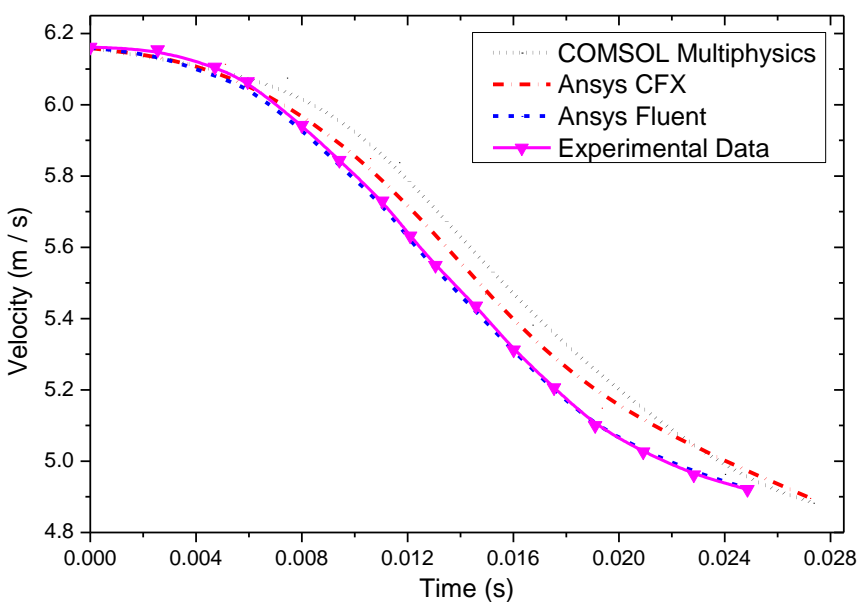

Figure 2. Comparison of the computed vertical velocity of the wedge by different softwares with the experimental data Zhao et al. (1996)

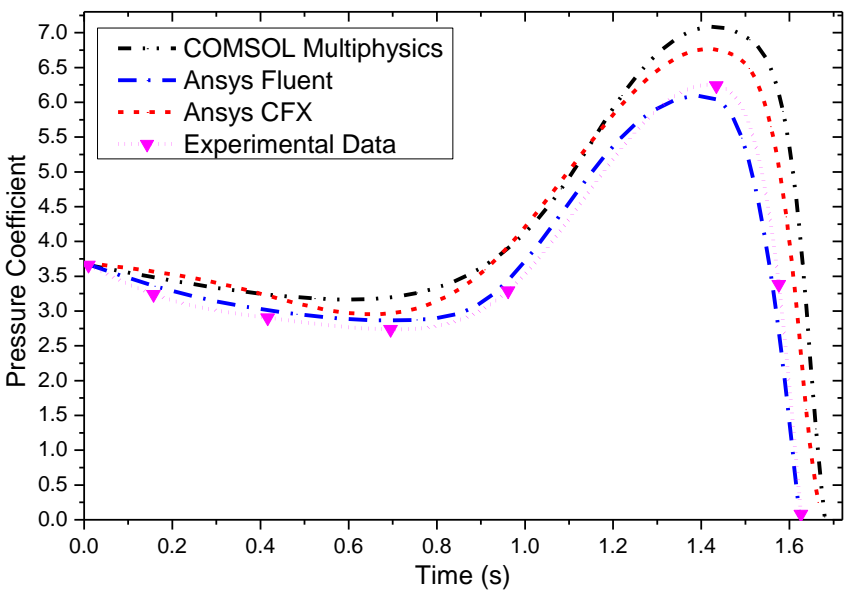

Figure 3. Comparison of the computed pressure coefficient by different softwares with the experimental data Zhao et al.

(1996)

The results of $\mathrm{k}-\varepsilon$ viscous model in ANSYS Fluent are the closest values to the experimental data against other viscous models as shown in Figure 4 and Figure 5. The grid independency has been studied by examining four different grid sizes (Table 1).

Table 1

\begin{tabular}{cc}
\hline Case & Number of Nodes \\
\hline 1 & 57810 \\
\hline 2 & 50328 \\
\hline 3 & 44085 \\
\hline 4 & 37416 \\
\hline
\end{tabular}

Figure 6 and Figure 7 depict histories of vertical

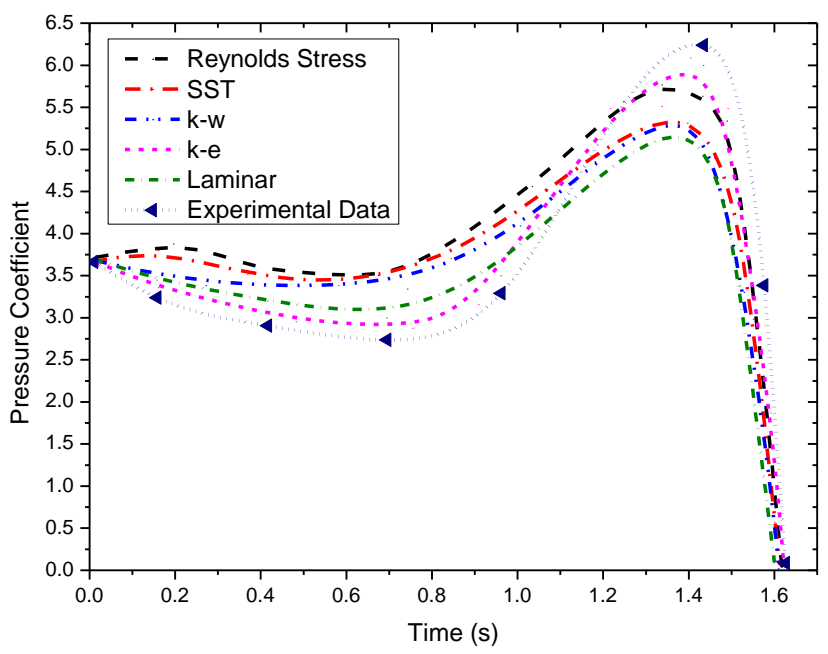

Figure 4. Comparison of the computed pressure coefficient with the experimental data Zhao et al. (1996) for different viscous models

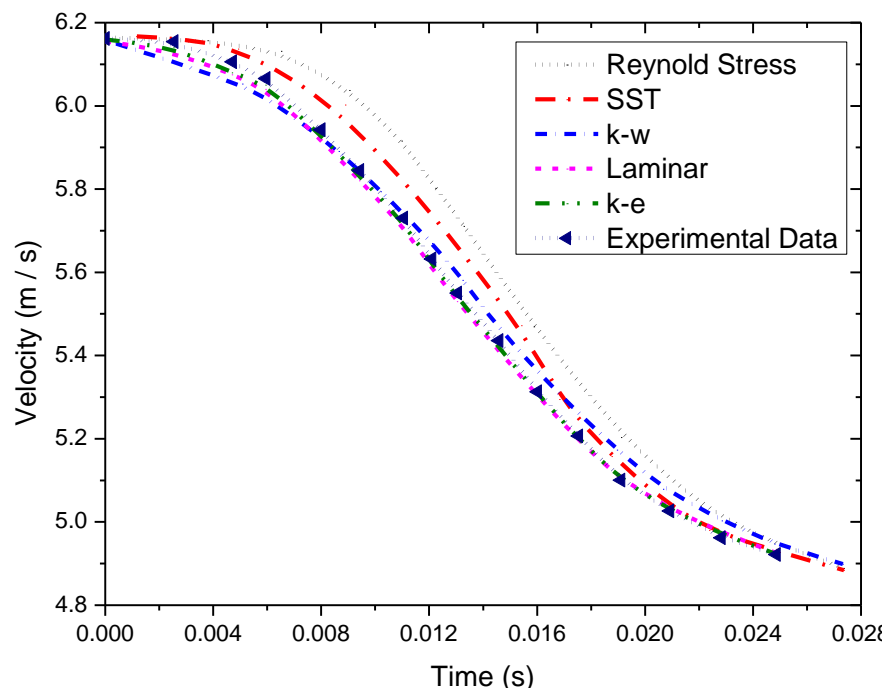

Figure 5. Comparison of the computed vertical velocity with the experimental data Zhao et al. (1996) for different viscous models

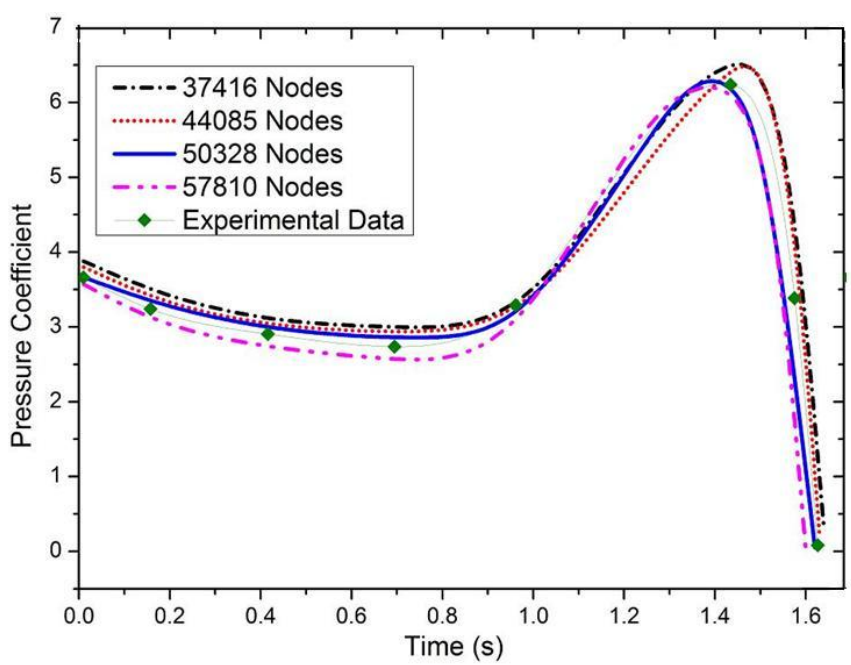

Figure 6. Comparison of the computed pressure coefficient with the experimental data Zhao et al. (1996) for grid independency evaluation

velocity and pressure coefficient distribution of the wedge during the water impact in all grid sizes, 
respectively. The corresponding experimental data are also provided for comparison. By comparing the results, it is apparent that the vertical velocity and pressure coefficient are calculated with more precision in the 50328 cells grid system. Hence, this grid system is adopted as the best one among other ones.

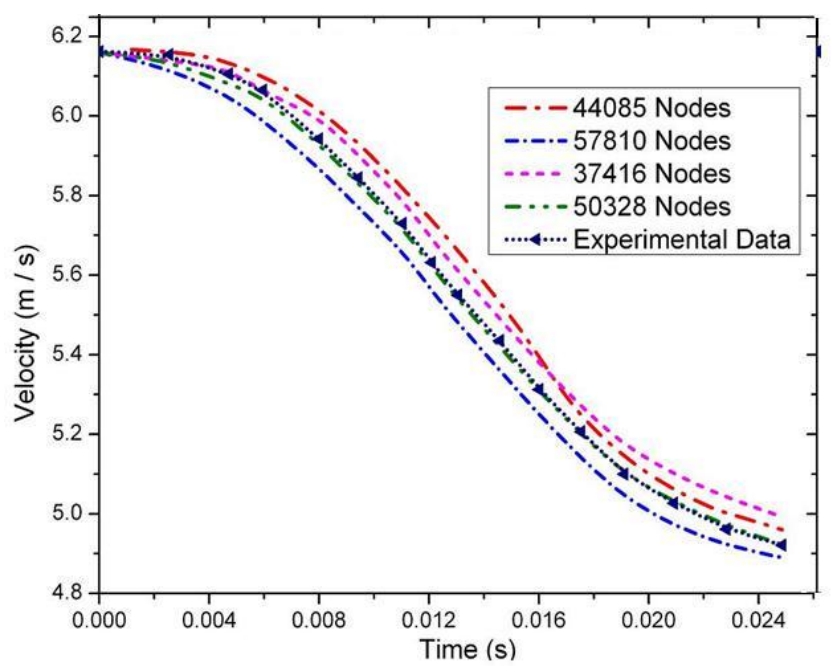

Figure 7. Comparison of the computed vertical velocity with the experimental data Zhao et al. (1996) for grid independency evaluation

\section{Results and Discussion}

In this study, three different numerical softwares are used to solve the dynamic equations of the motion. As mentioned, these softwares were ANSYS Fluent, ANSYS CFX and COMSOL Multiphysics. The geometry of simulation was meshed with nearly 50000 cells. The present numerical results are in a good agreement with the experimental data, especially ANSYS Fluent. The comparison of them after touching the water by wedge was shown. The k- $\varepsilon$ viscous model had close results to experimental data. The difference between the present numerical results and the experimental data may be due to the three dimensional effects which are not modelled here. It is interesting that the pressure coefficient which is of importance in structural design is in a good agreement with experiments although the 3-D effect is not taken into account. The oscillations of pressure distribution can be due to remeshing around the wedge which occurs in this method.

The grid independence has been studied by examining four different grid sizes for pressure coefficient. In the 50328 cells grid system, the vertical velocity and pressure coefficient are calculated with more precision. Hence, this grid system is adopted as the best one among others. Changing the mesh system mainly affects the free surface shape accuracy and fluid reaction, consequently. For deducing the effect of turbulent flow in this problem due to high Reynolds number, some turbulence model such as $\mathrm{k}-\varepsilon, \mathrm{k}-\mathrm{w}$, Shear Stress Transport (SST) and Reynolds Stress versus laminar model were applied to simulate the flow around the wedge by three different numerical solvers. The laminar and turbulent viscous models are implemented. The time history of vertical velocity, vorticity, drag coefficient, pressure coefficient, total pressure, static pressure, dynamic pressure, hydrodynamic force and turbulence intensity are computed for any of five different viscous models and compared with each other in ANSYS Fluent and ANSYS CFX (without $k-\omega$ viscous model). The time history of mentioned parameters are computed for laminar and $\mathrm{k}-\varepsilon$ viscous model in COMSOL Multiphysics. The results show that the predictions of turbulence models are close to laminar simulation in ANSYS CFX and COMSOL Multiphysics unlike ANSYS Fluent. It may be due to the fact that pressure force is nearly dominant during the water impact problem and also no vortex formation can be observed in resulted wave patterns of these two softwares, ANSYS CFX and COMSOL Multiphysics. Therefore, it is better to use laminar flow instead of turbulent flow modeling in simulation by these two softwares which is accompanied by solving additional flow equations and leads to higher computational costs. The geometry of twin two dimensional falling wedges was shown in Figure 8.

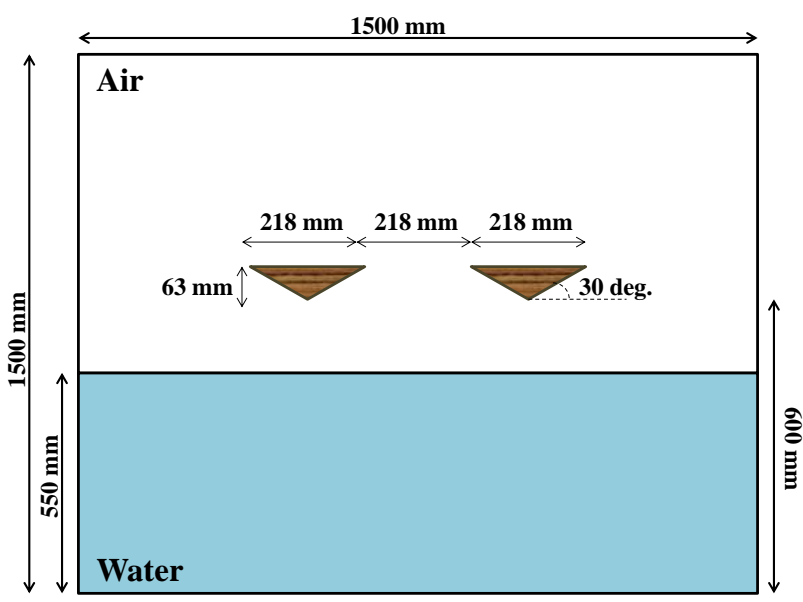

Figure 8. Geometrical configuration of the present study

\subsection{ANSYS FLUENT}

The results of ANSYS Fluent simulation for twin two dimensional falling wedges were shown in Figure 9 to 13 for laminar, $\mathrm{k}-\varepsilon, \mathrm{k}-\omega$, Reynolds stress and SST models, respectively. In each figure, the free surface pattern due to impact has been shown till $0.25 \mathrm{~s}$ after falling start of twin wedges. Free surface pattern is different for simulation with various viscous models by ANSYS Fluent. Comparison of pressure coefficient with different viscous models by ANSYS Fluent was shown in Figure 14.

The pressure coefficient is computed by equation (8): 


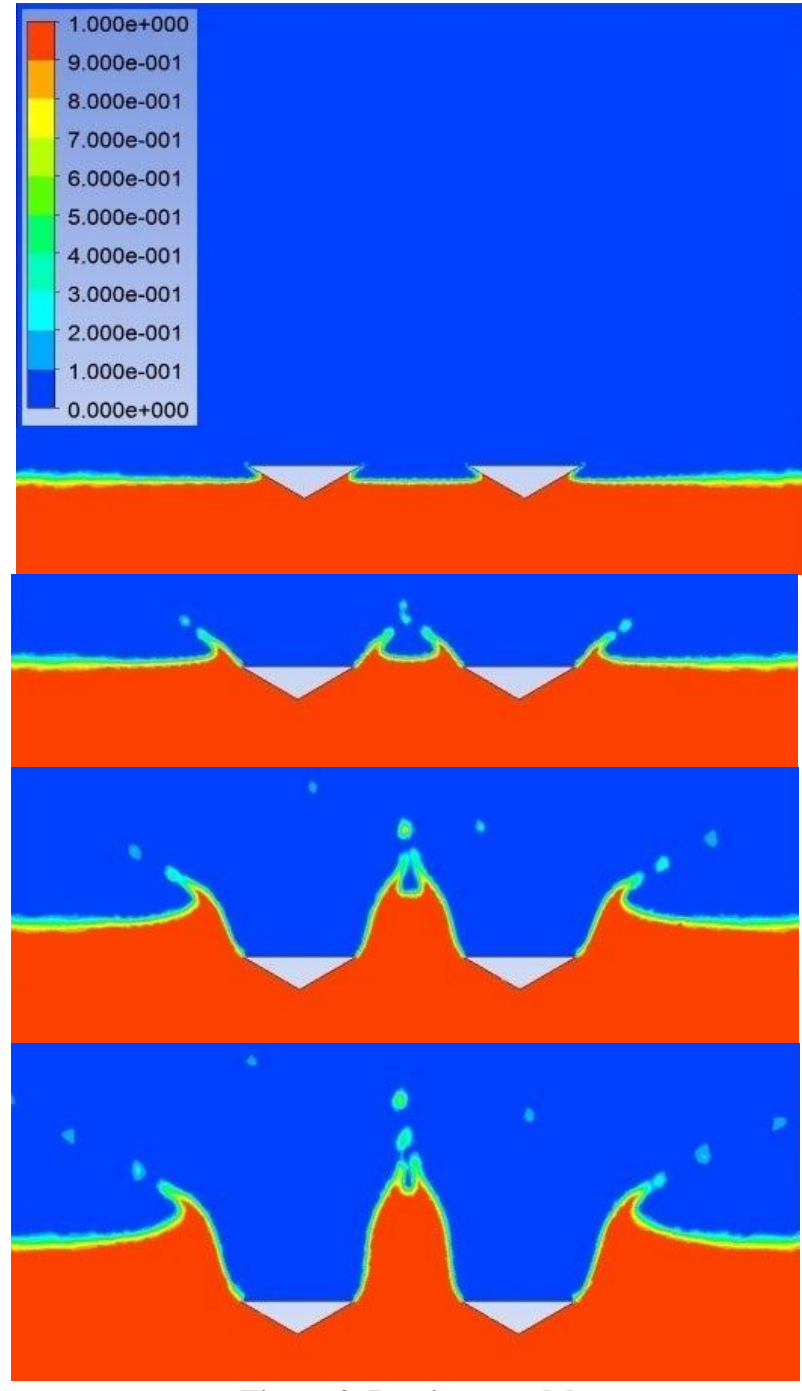

Figure 9. Laminar model

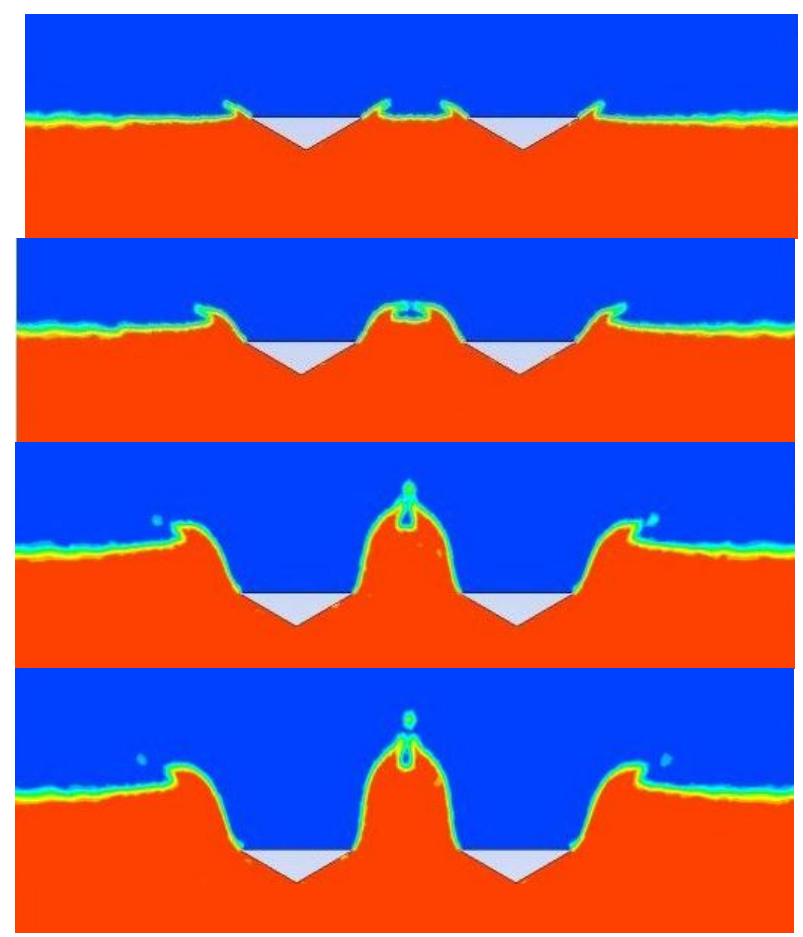

Figure 10. k- $\varepsilon$ model

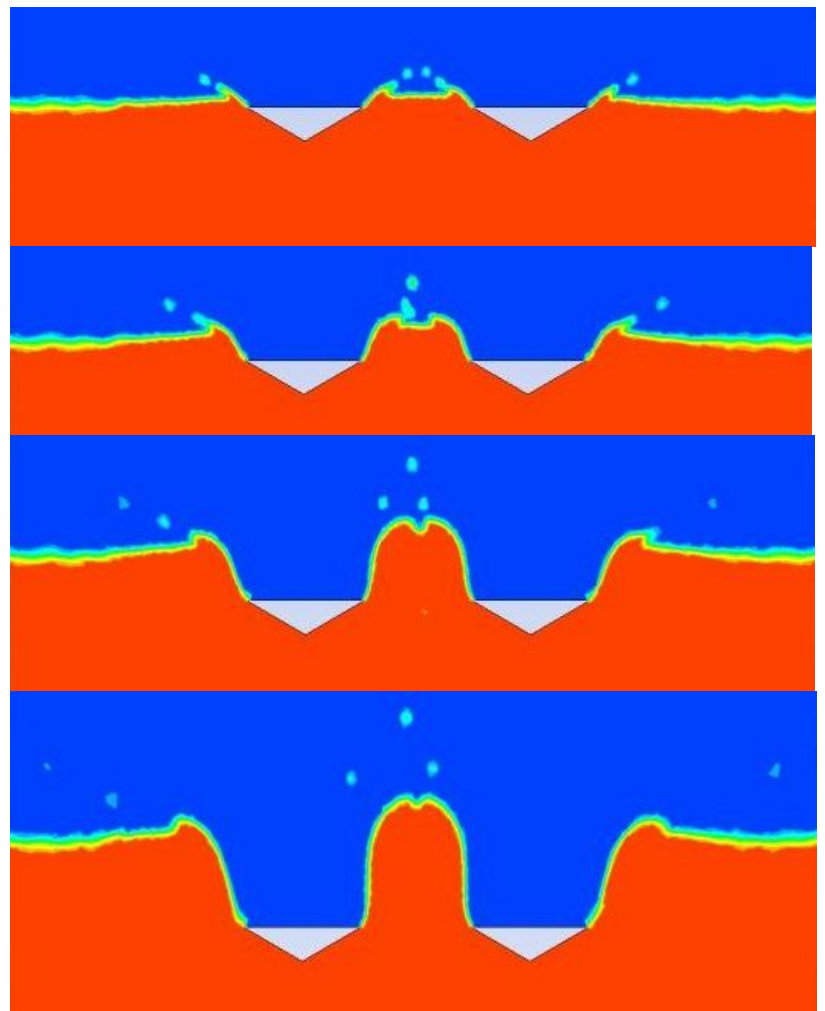

Figure 11. k- $\omega$ model

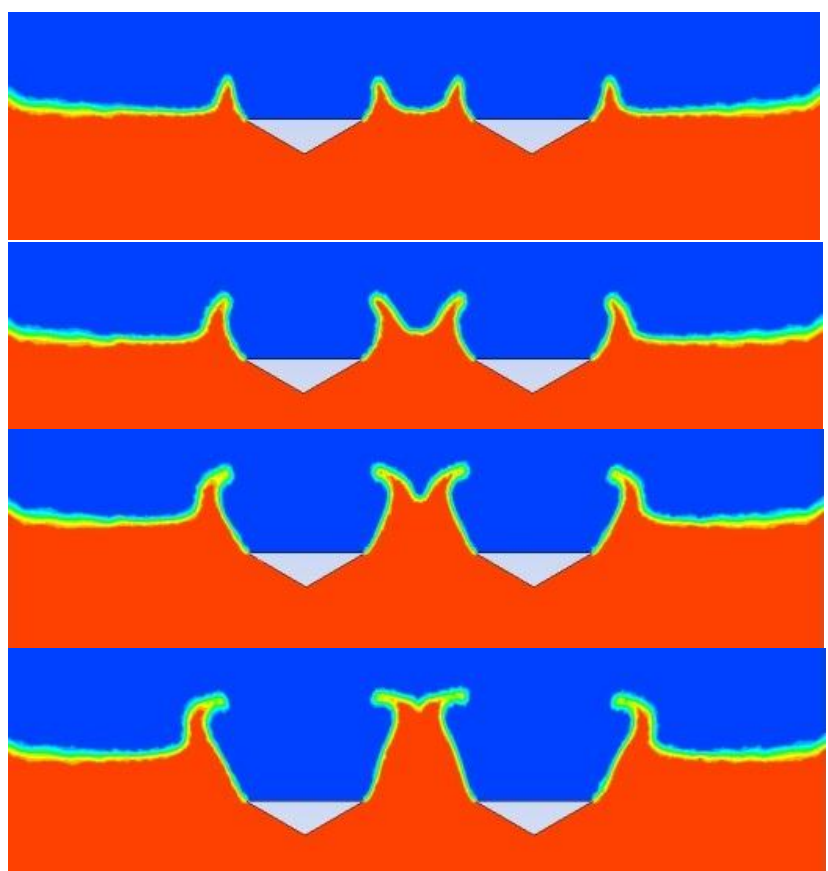

Figure 12. Reynolds Stress model

$C_{p}=2 P / \rho V_{w}^{2}$

where $\mathrm{P}, \rho$ and $\mathrm{V}_{\mathrm{w}}$ are static pressure, water density and the velocity of the wedges at time $t$, respectively. The drag coefficient is a dimensionless quantity that is used to quantify the drag or resistance of wedges in peripherial fluids, such as air or water. 


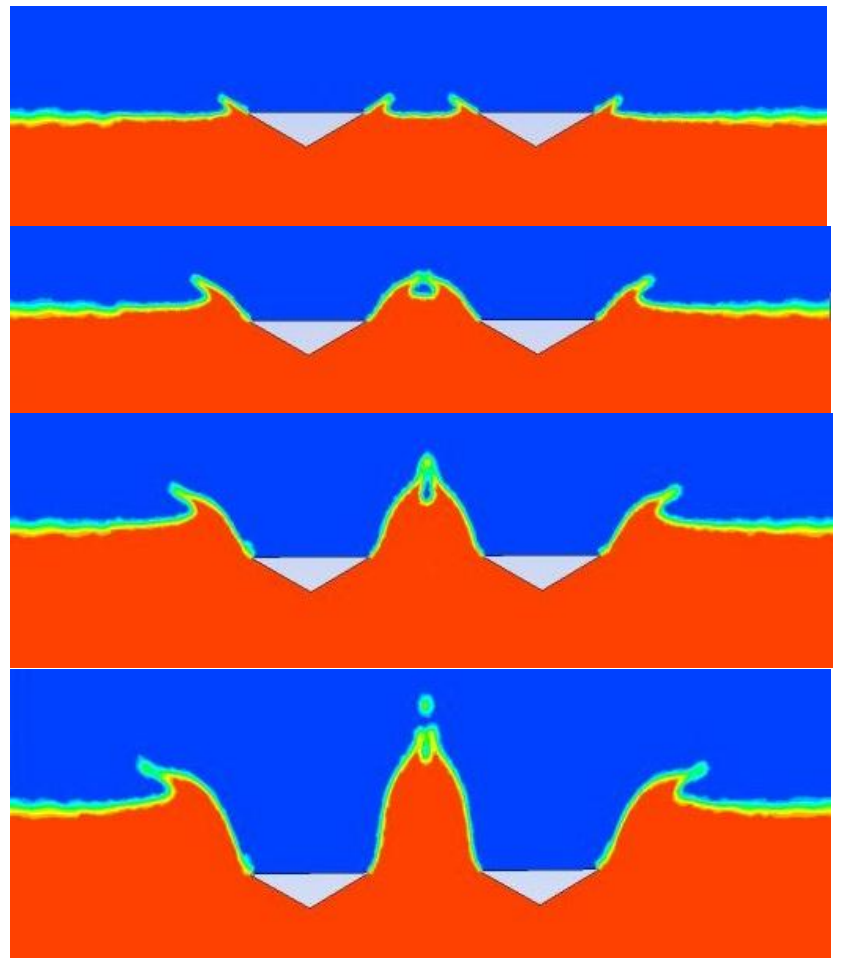

Figure 13. SST model

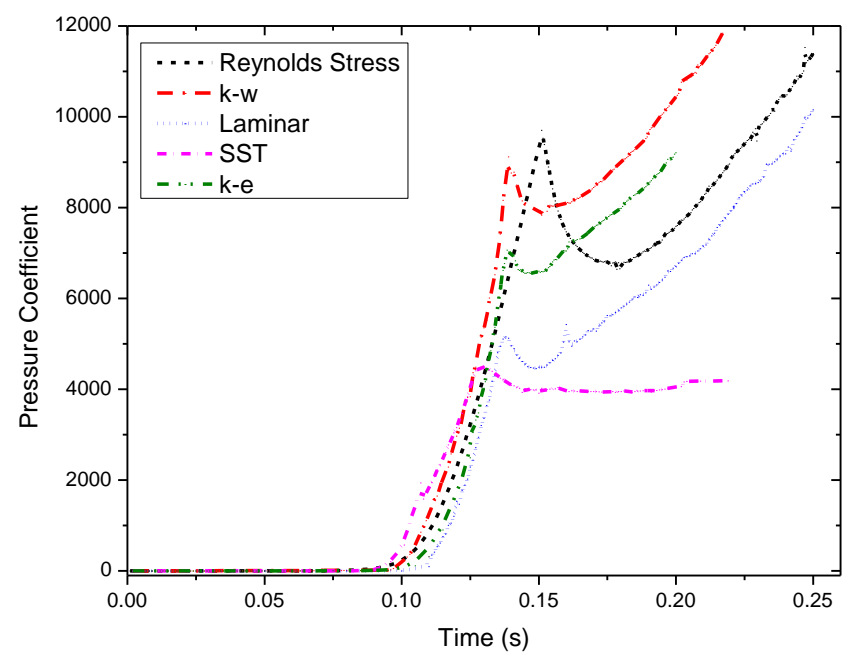

Figure 14. Comparison of pressure coefficient with different viscous models

It is computed by:

$$
C_{d}=2 F_{d} / \rho V_{w}^{2} A
$$

where $F_{d}, \rho, V_{w}$ and $A$ are drag fore (aerodynamic or hydrodynamic drag), peripherial fluid density, vertival velocity and projected area of wedges, respectively. The drag coefficient is shown in Figure 15 for all viscous models by ANSYS Fluent. The total pressure and dynamic pressure were shown in Figure 16 and Figure 17. The total pressure refers to the sum of static pressure, dynamic pressure and gravitational head. The vertical velocity of wedges for all viscous models is shown in Figure 18. At first, the vertical velocity of each wedges increases rapidly but after

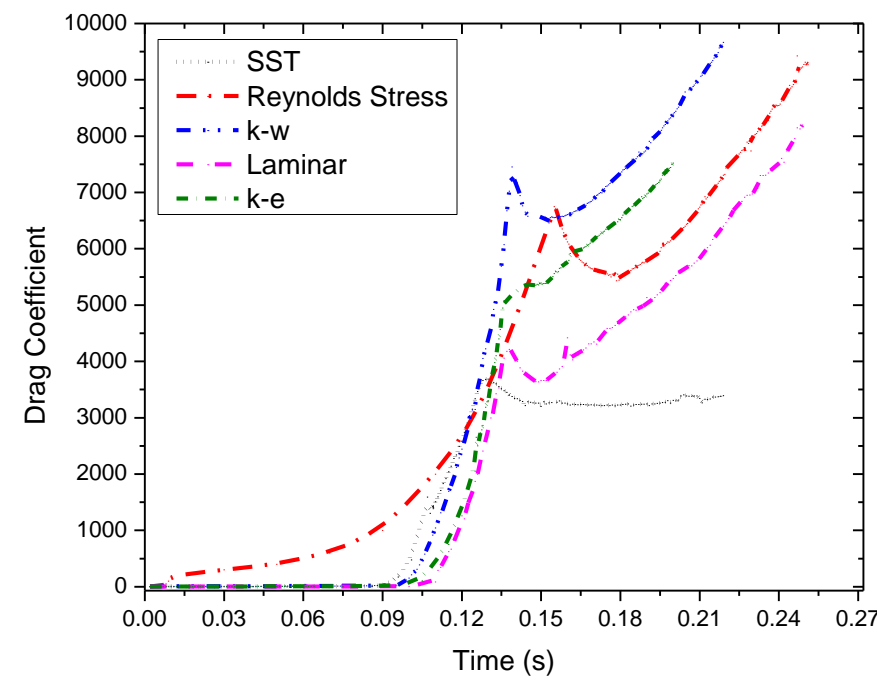

Figure 15. Comparison of drag coefficient with different viscous models

wedges impact, it decrease smoothly till to reach ultimate velocity.

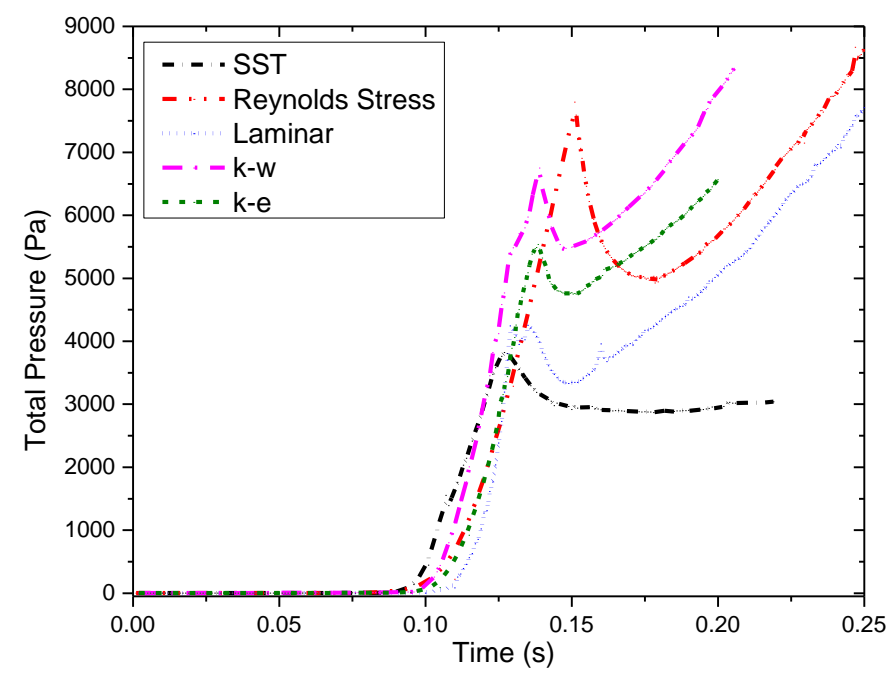

Figure 16. Comparison of total pressure with different viscous models

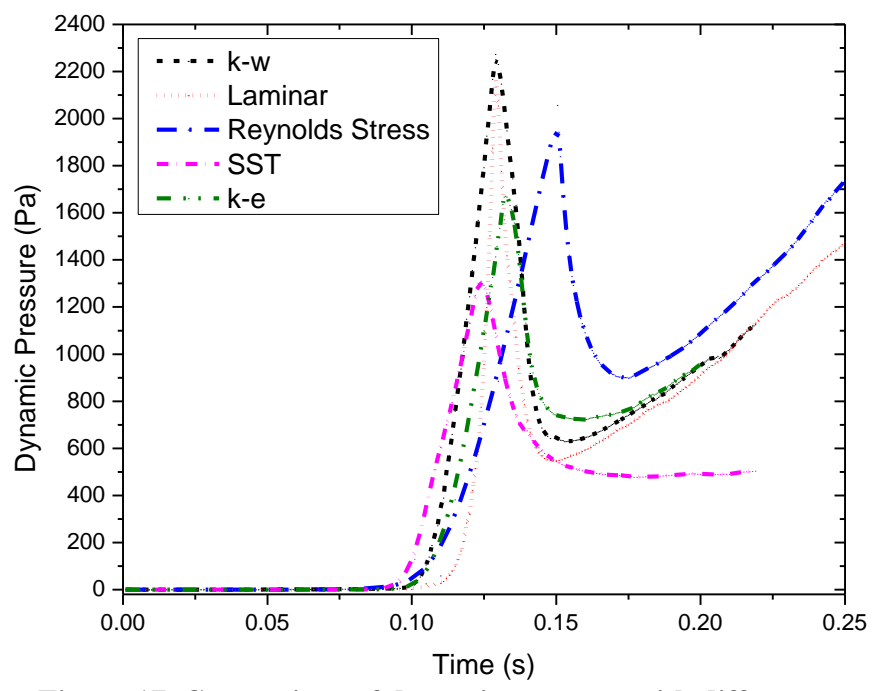

Figure 17. Comparison of dynamic pressure with different viscous models 


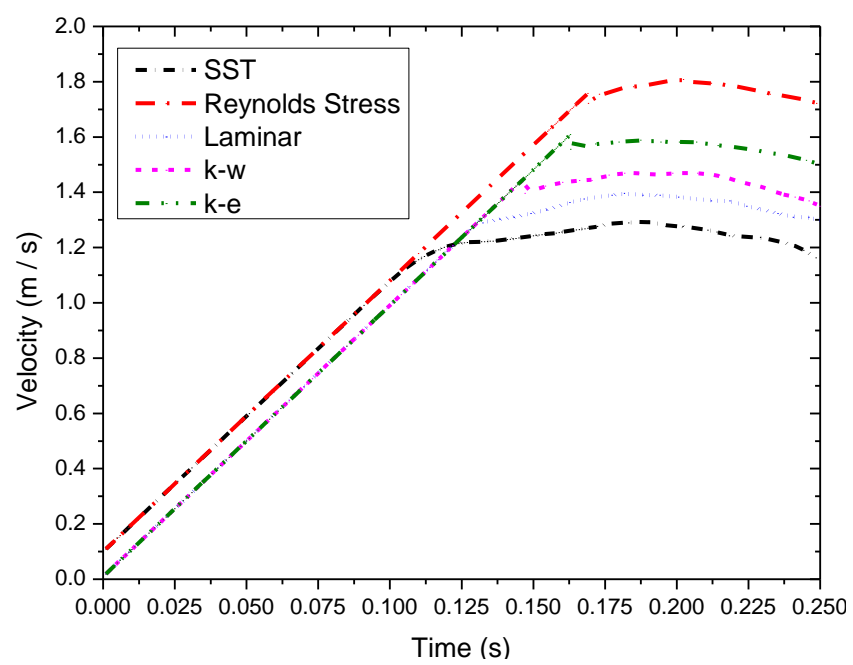

Figure 18. Comparison of vertical velocity with different viscous models

The turbulence intensity, also often referred to as turbulence level, is defined as:

$$
\begin{aligned}
& I=u^{\prime} / U \\
& u^{\prime}=\sqrt{\left(u_{x}^{\prime 2}+u_{y}^{\prime 2}\right) / 3}=\sqrt{2 k / 3}
\end{aligned}
$$

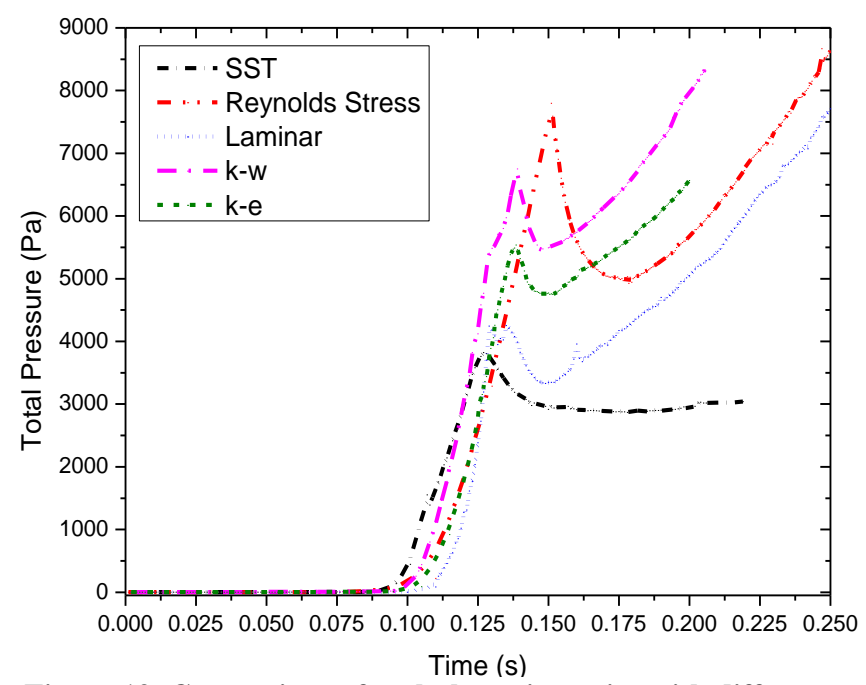

Figure 19. Comparison of turbulence intensity with different viscous models

where $\mathrm{u}^{\prime}$ is the root-mean-square of the turbulent velocity fluctuations and $\mathrm{U}$ is the mean velocity. If the turbulent energy, $\mathrm{k}$ is known u' can be calculated by equation (11) for two dimensional problems.

The vorticity is a pseudo-vector field that describes the local spinning motion of a continuum near some point or the tendency of something to rotate. It is computed by equation (12) and (13):

$\vec{\omega}=\omega_{x} \hat{\mathrm{i}}+\omega_{y} \hat{\mathrm{j}} \equiv \nabla \times \vec{V}$

Vorticity Magnitude $=\sqrt{\omega_{x}^{2}+\omega_{y}^{2}}$
The vorticity was shown in Figure 20 for viscous models by ANSYS Fluent. The computed drag force was shown in Figure 21.

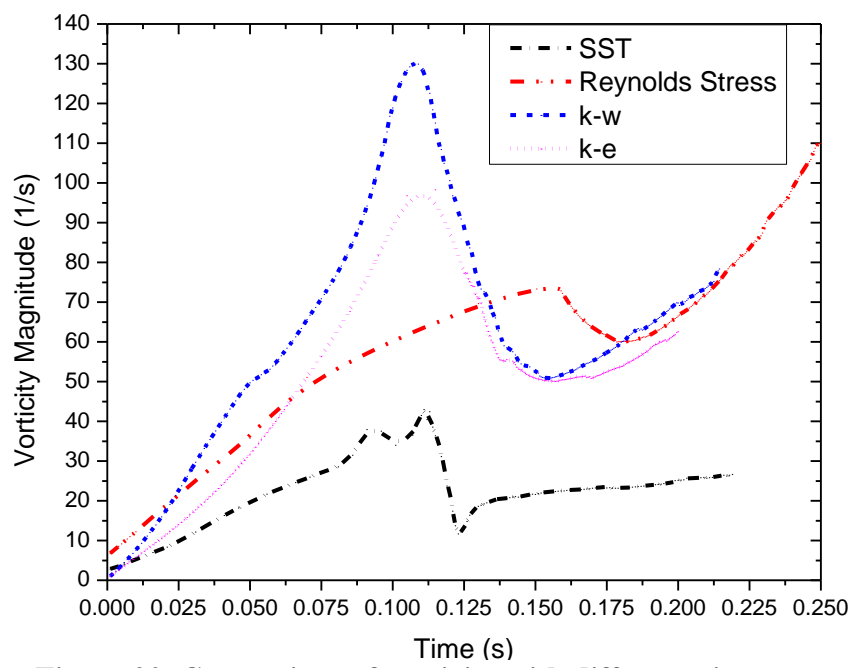

Figure 20. Comparison of vorticity with different viscous models

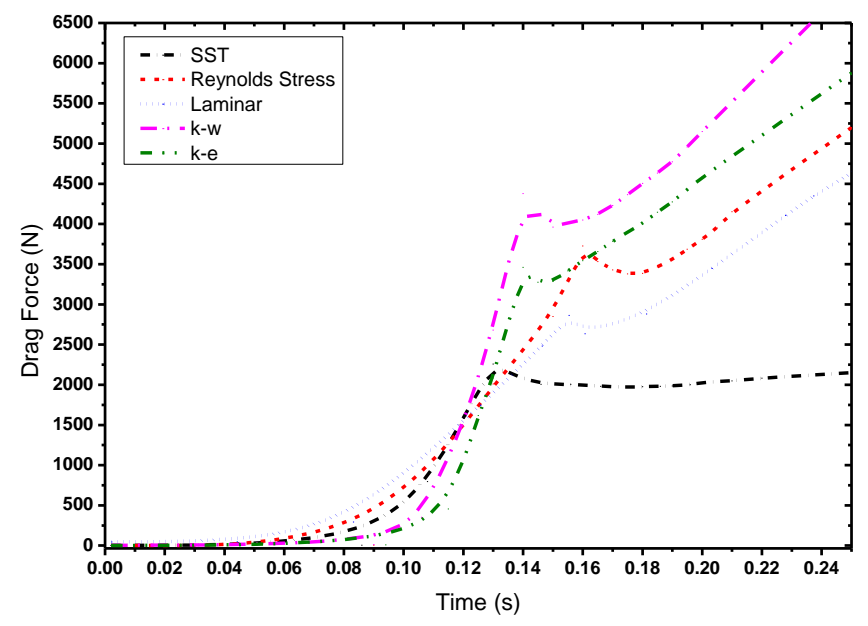

Figure 21. Comparison of drag force with different viscous models

Definition of $Z$ and $D$ was depicted in Figure 22. The $\mathrm{Z} / \mathrm{D}$ ratio was shown in Figure 23. $\mathrm{Z}$ is the maximum height of water from the initial flat free surface and $D$ is the altitude of triangle. For initial time, Z/D ratio equals 8.73 .

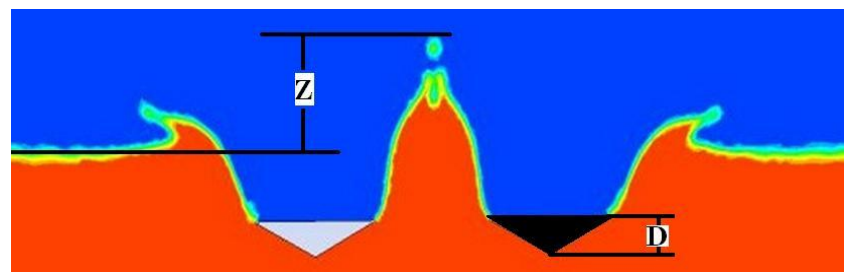

Figure 22. $\mathrm{Z}$ and D definition 


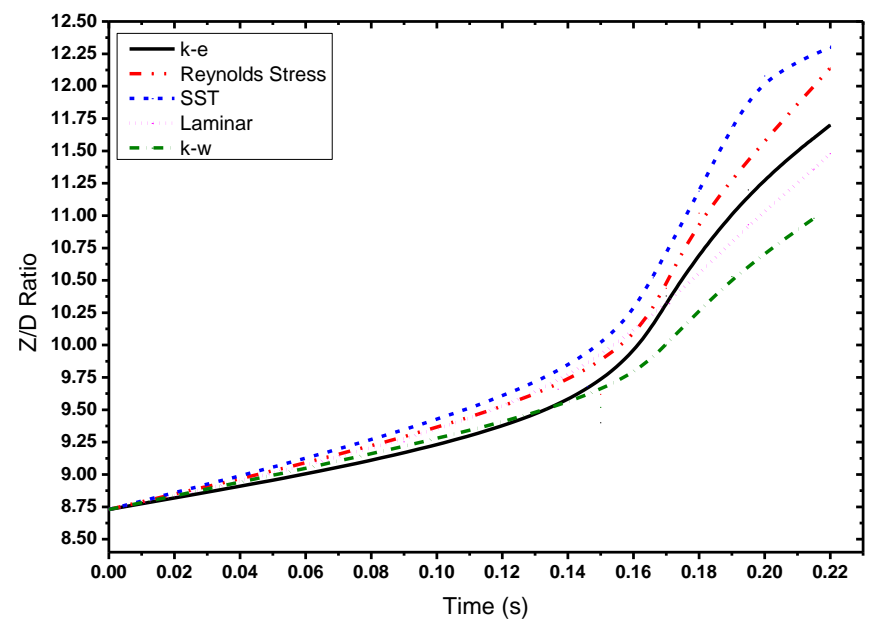

Figure 23. Comparison of $\mathrm{Z} / \mathrm{D}$ ratio with different viscous models

\subsection{ANSYS CFX}

The results of ANSYS CFX solver for twin two dimensional falling wedges were shown in Figure 24 for all laminar, $\mathrm{k}-\varepsilon$, Reynolds stress and SST models.
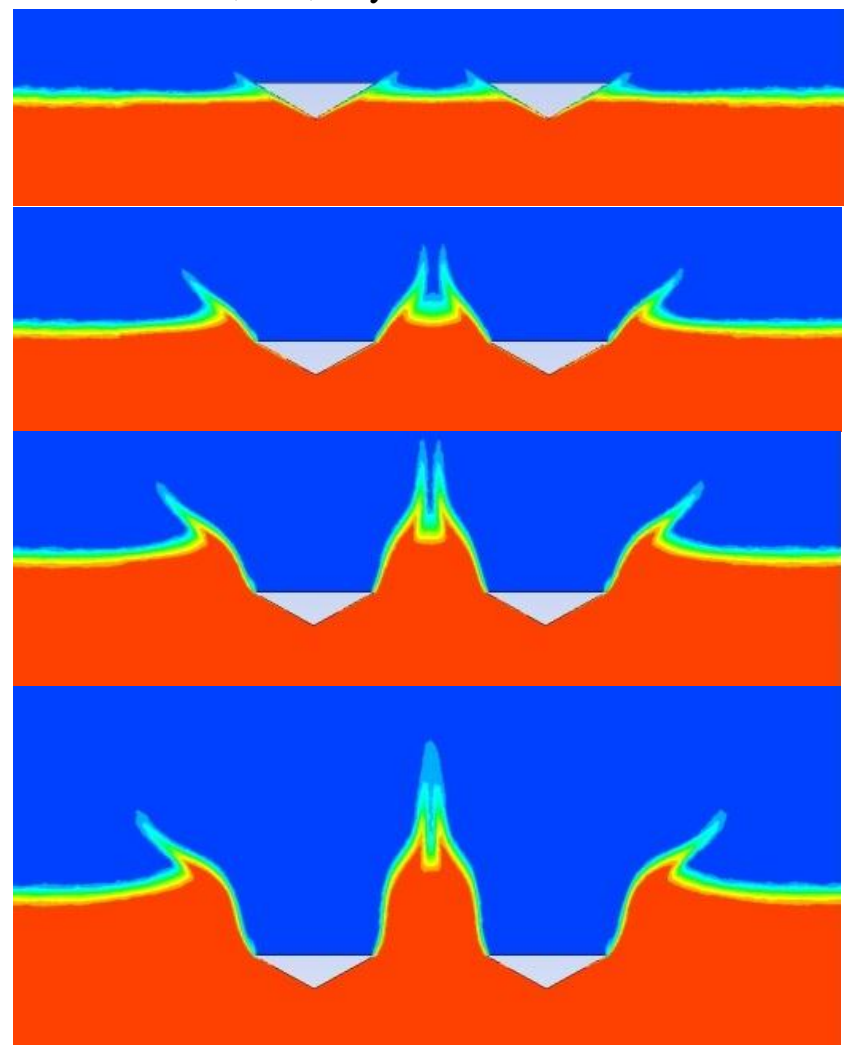

Figure 24. For all viscous models

The $\mathrm{k}-\omega$ model is not defined as default turbulent viscous model in ANSYS CFX. There is no sensible difference between free surface patterns by all viscous models in this software. The comparison of pressure coefficient with different viscous models by ANSYS CFX was shown in Figure 25. The drag coefficient was shown in Figure 26 for all viscous models by ANSYS CFX.

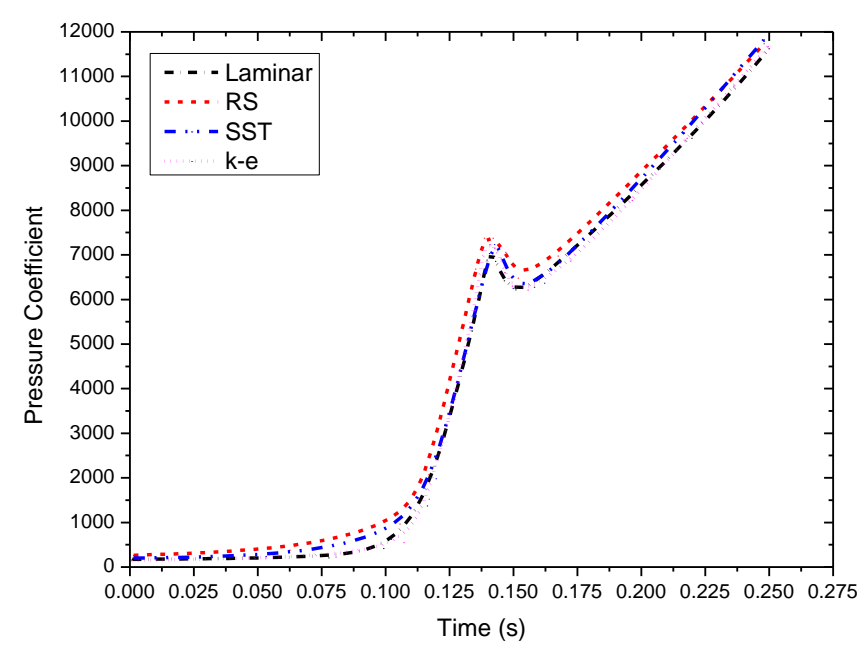

Figure 25. Comparison of pressure coefficient with different viscous models

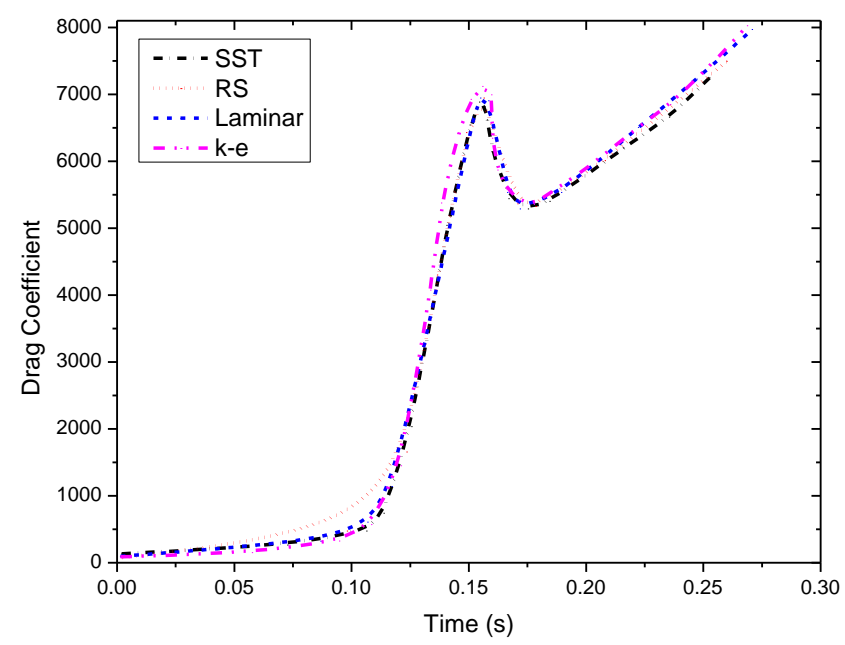

Figure 26. Comparison of drag coefficient with different viscous models

The results show that the predictions of turbulence models are close to laminar simulation in ANSYS CFX. The total pressure and dynamic pressure were shown in Figure 27 and Figure 28.

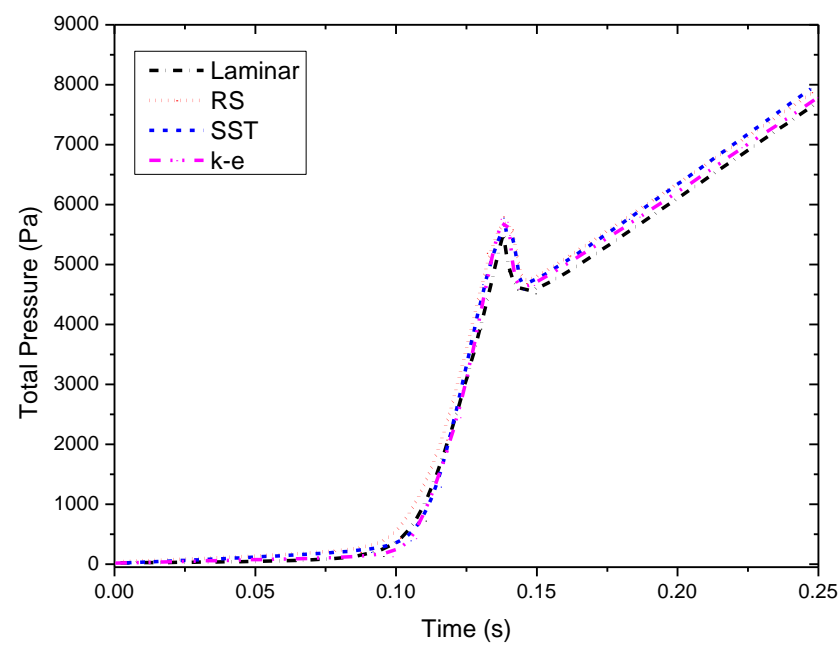

Figure 27. Comparison of total pressure with different viscous models 


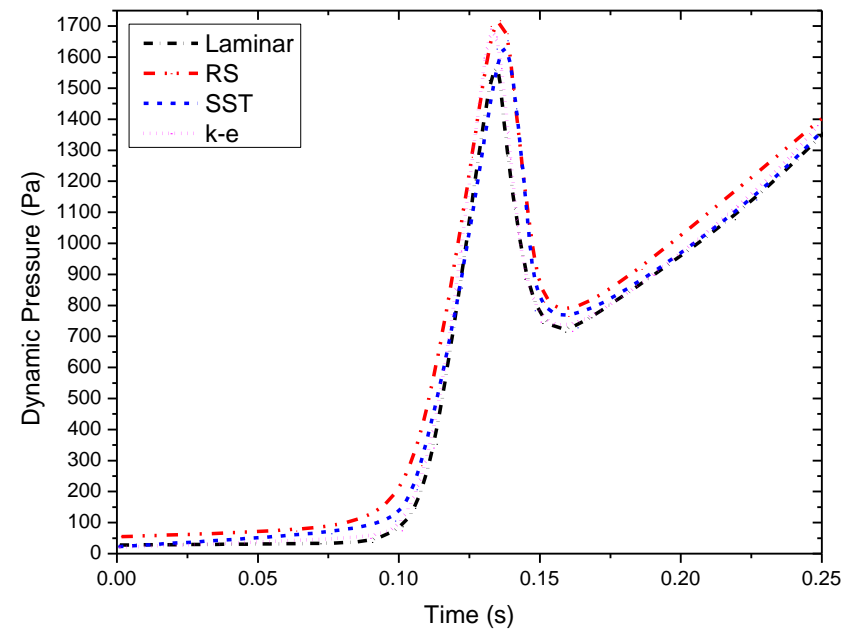

Figure 28. Comparison of dynamic pressure with different viscous models

Vertical velocity was shown in Figure 29 for all viscous models by ANSYS CFX.

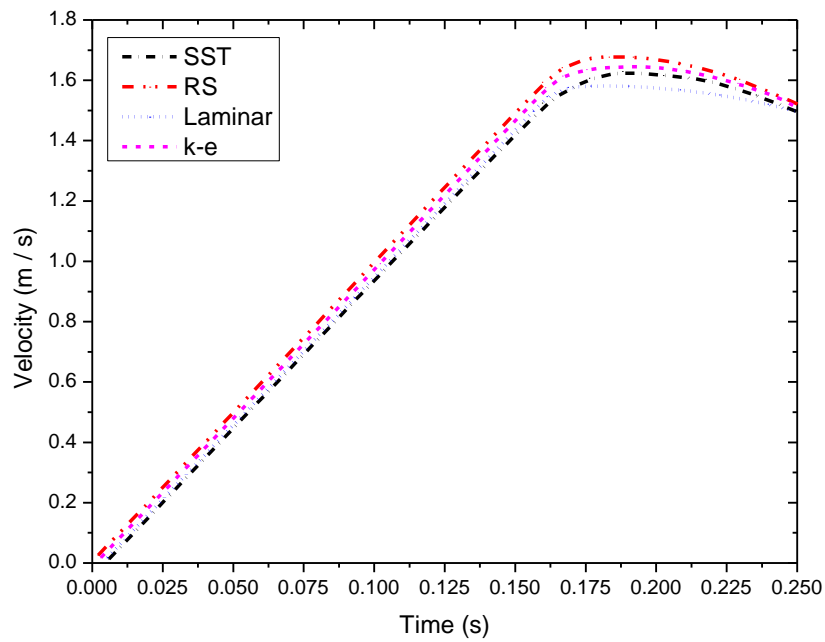

Figure 29. Comparison of vertical velocity with different viscous models

The comparison of turbulence intensity and vorticity magnitude are shown for three turbulent viscous models by ANSYS CFX in Figure 30 and Figure 31.

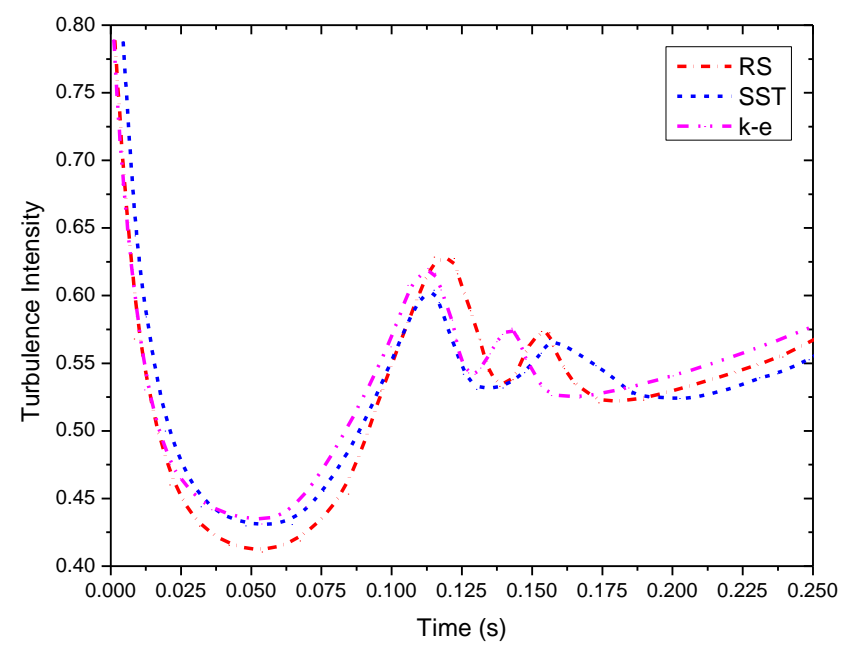

Figure 30. Comparison of turbulence intensity with different viscous models

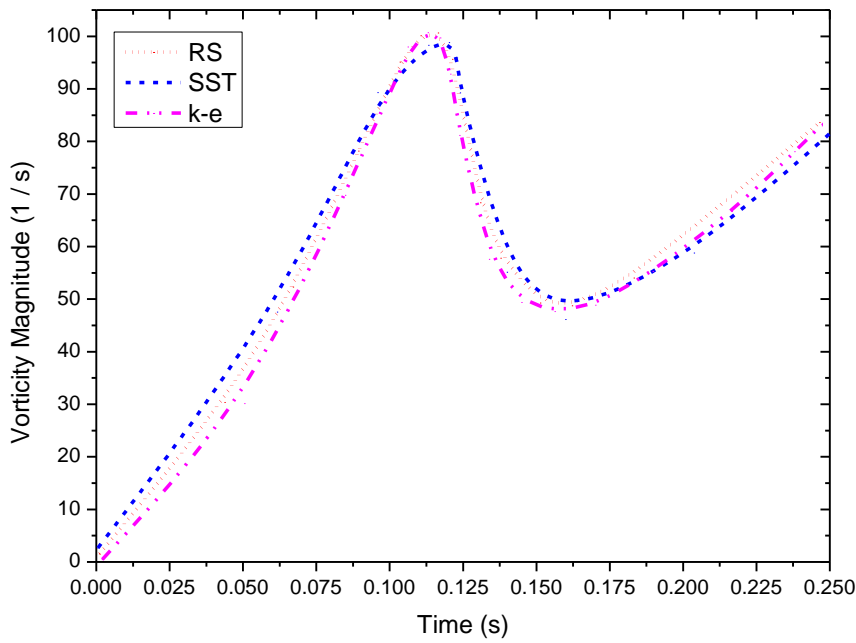

Figure 31. Comparison of vorticity with different viscous models

The drag force and Z/D ratio were shown in Figure 32 and Figure 33 for all different viscous models by ANSYS CFX, respectively.

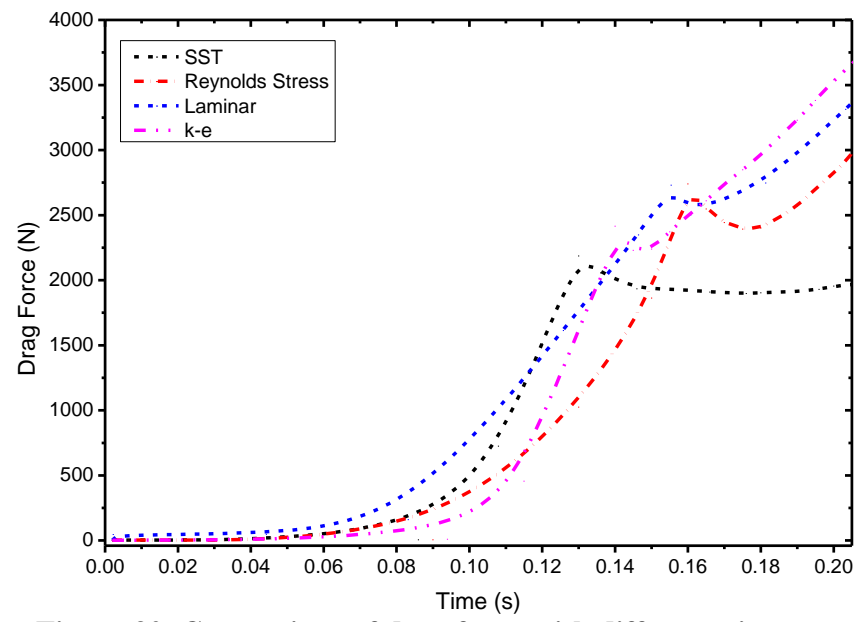

Figure 32. Comparison of drag force with different viscous models

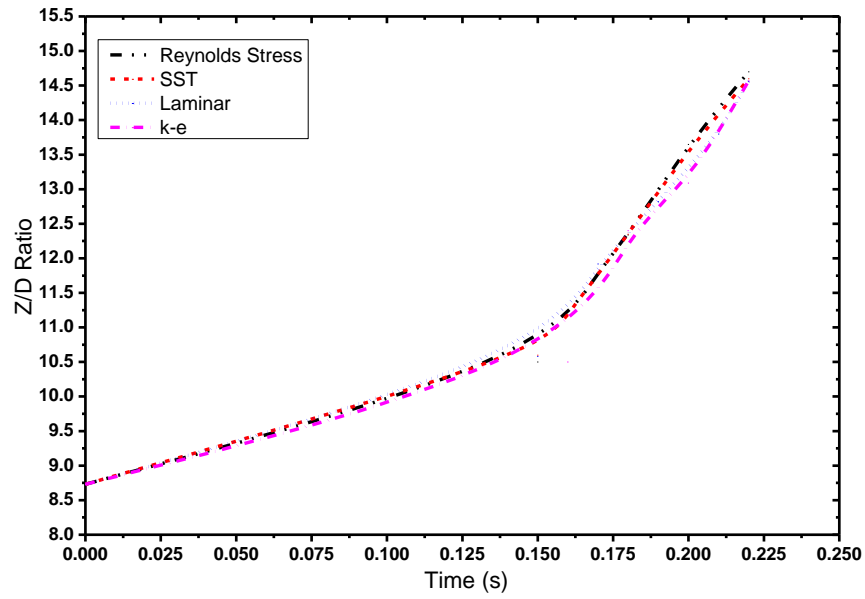

Figure 33. Comparison of $\mathrm{Z} / \mathrm{D}$ ratio with different viscous models

\subsection{COMSOl MultiPhysics}

The results of COMSOL simulation for twin two dimensional falling wedges by were shown in Figure 34 for laminar and k- $\varepsilon$ models. The k- $\omega$, Reynolds 
stress and SST models are not defined as default turbulent viscous model in COMSOL Multiphysics. There is no sensible difference between patterns of waves by these two viscous models in this software.
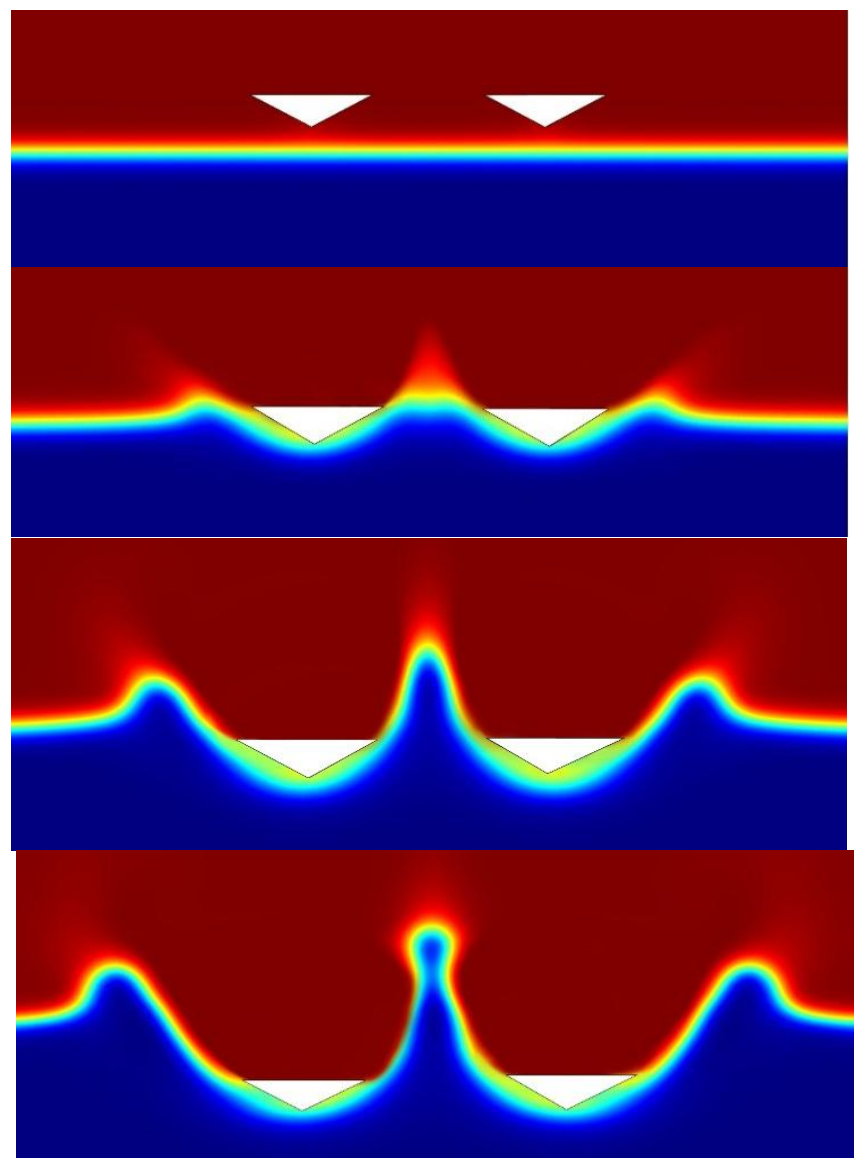

Figure 34. For all viscous models

The comparison of pressure coefficient with different viscous models by COMSOL Multiphysics was shown in Figure 35. The comparison of drag coefficient with different viscous models by COMSOL Multiphysics was shown in Figure 36. The total pressure and dynamic pressure were shown in Figure 37 and Figure 38.

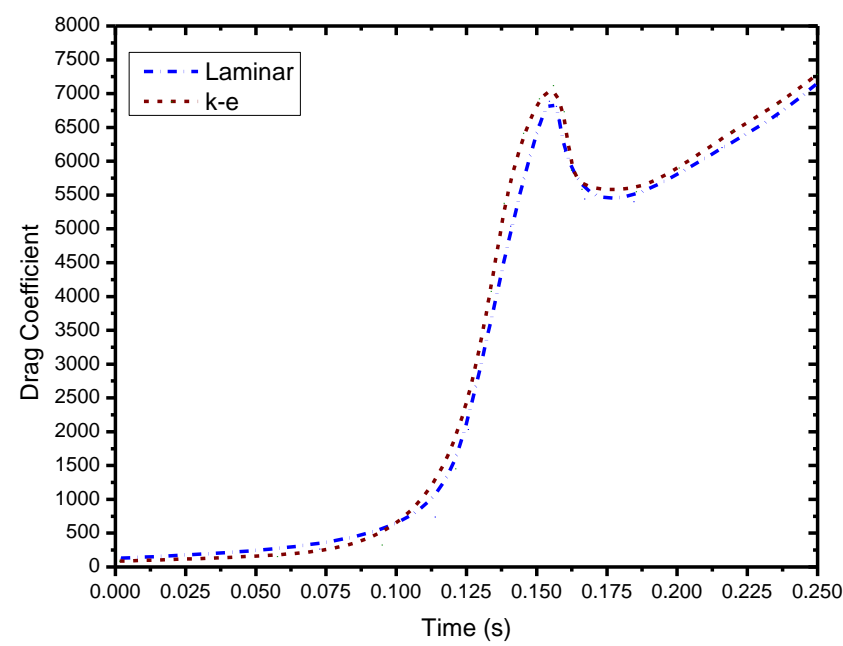

Figure 35. Comparison of pressure coefficient with different viscous models

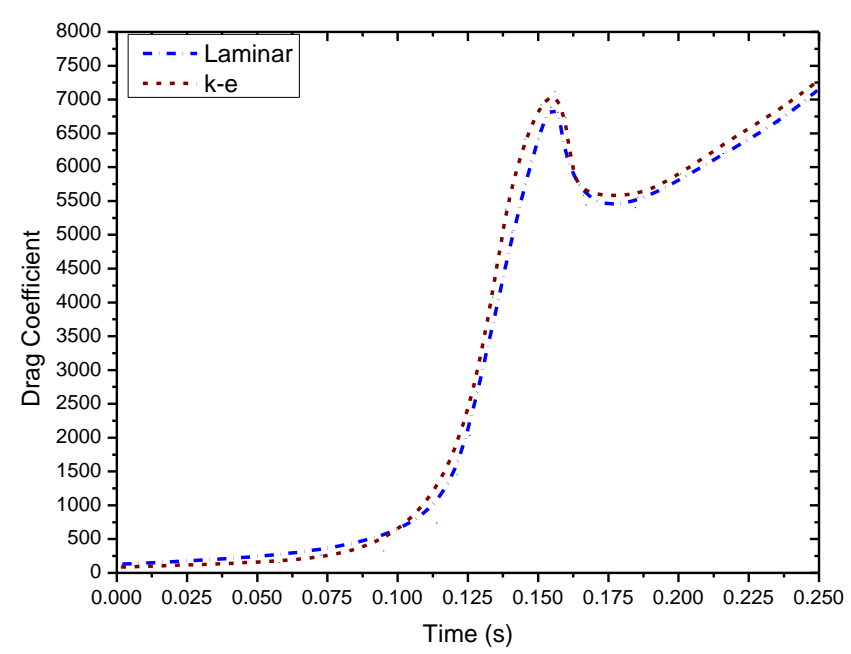

Figure 36. Comparison of drag coefficient with different viscous models

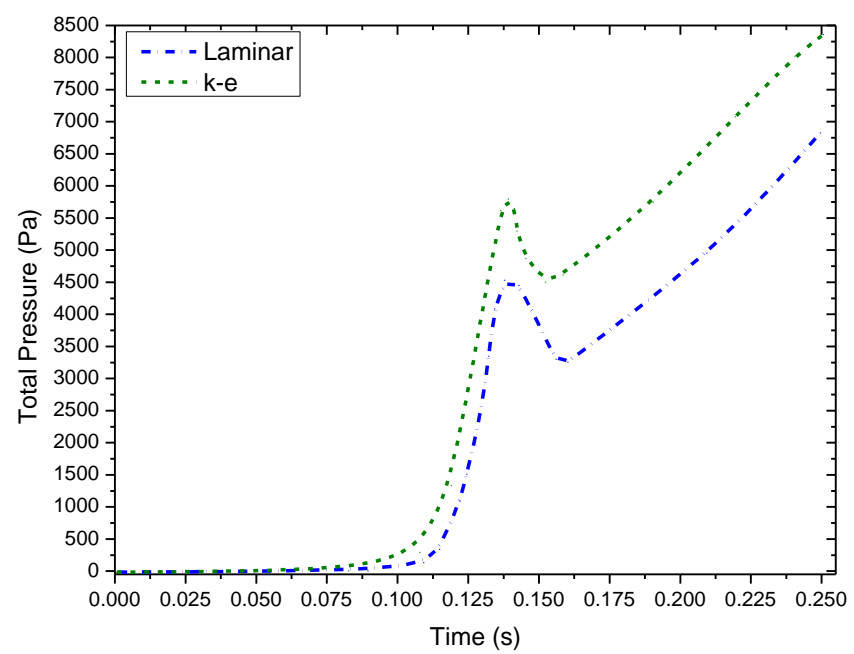

Figure 37. Comparison of total pressure with different viscous models

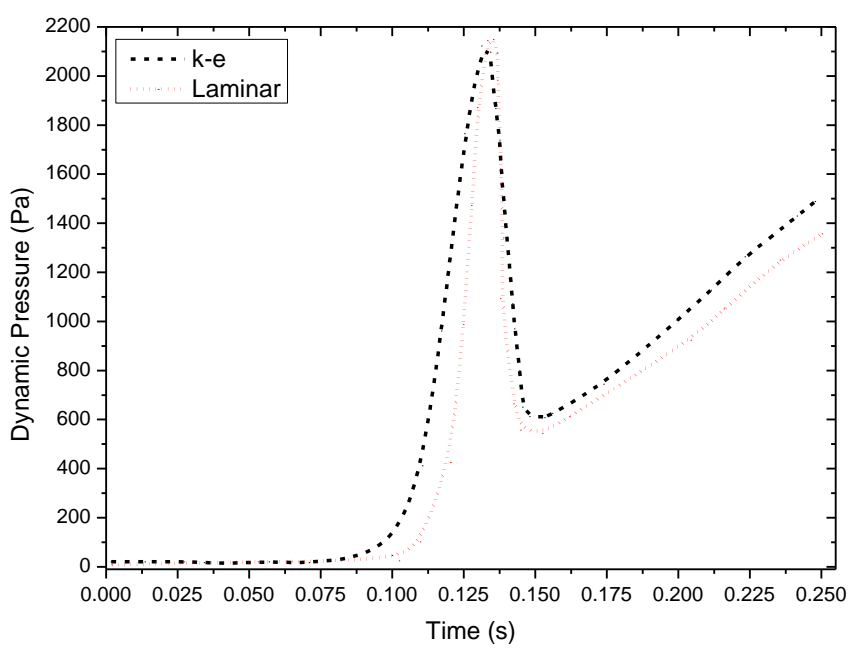

Figure 38. Comparison of dynamic pressure with different viscous models

The vertical velocity is shown in Figure 39 for all viscous models by COMSOL Multiphysics. 


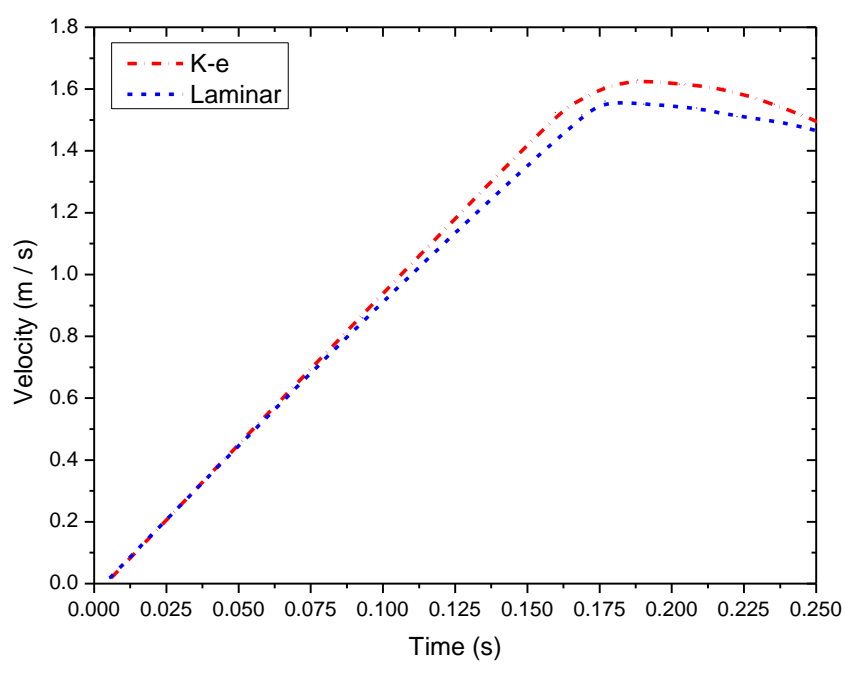

Figure 39. Comparison of vertical velocity with different viscous models

The turbulence intensity and vorticity magnitude for $\mathrm{k}-\varepsilon$ turbulent viscous model by COMSOL Multiphysics are shown in Figure 40 and Figure 41, respectively.

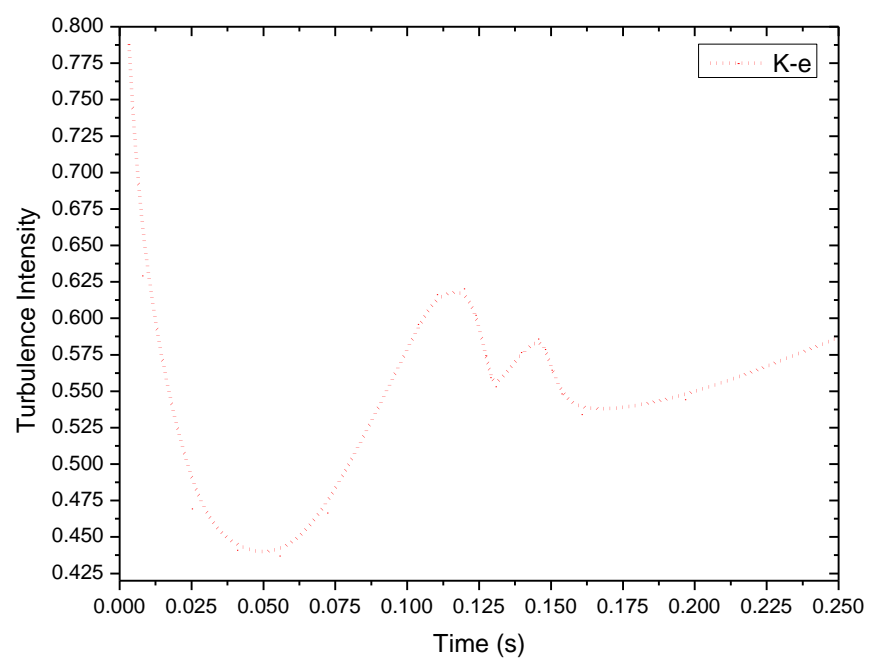

Figure 40. Comparison of turbulence intensity with $k-\varepsilon$ model

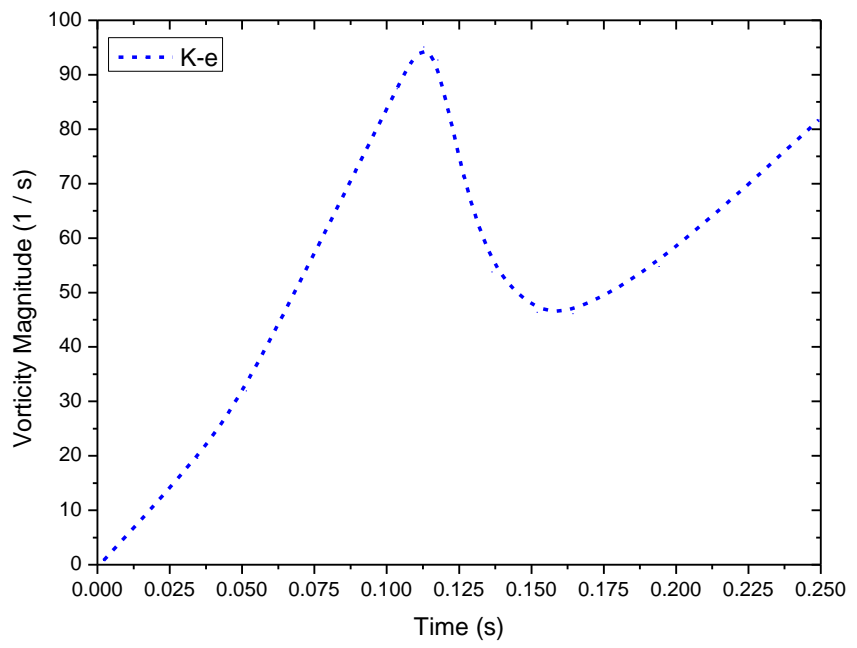

Figure 41. Comparison of vorticity with k-e model
The drag force and Z/D ratio were shown in Figure 42 and Figure 43 for all different viscous models by COMSOL Multiphysics, respectively.

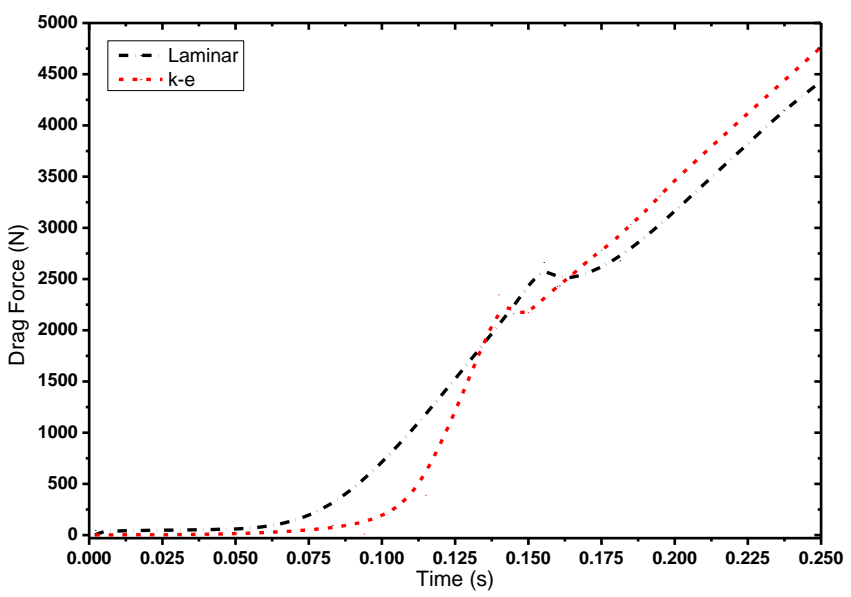

Figure 42. Comparison of drag force with different viscous models

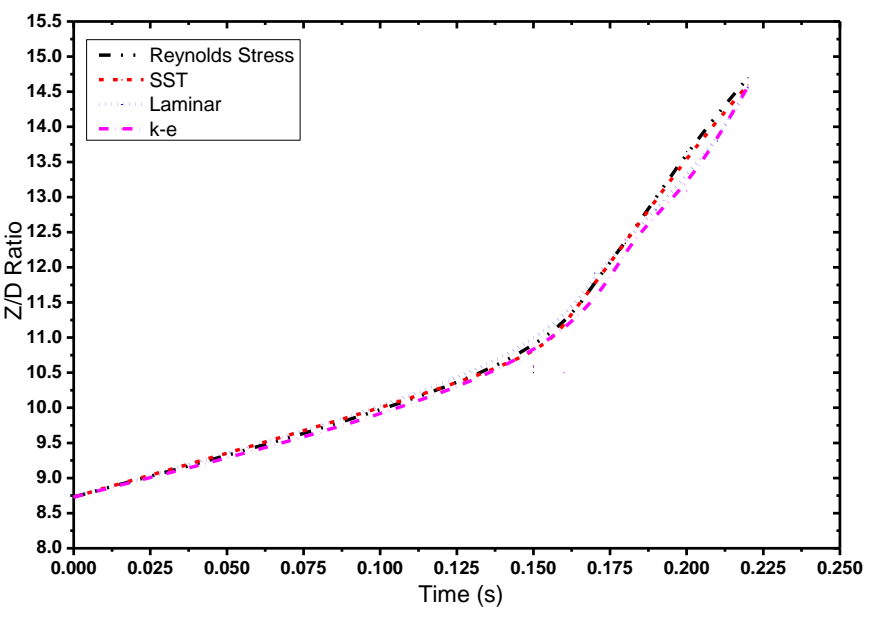

Figure 43. Comparison of $\mathrm{Z} / \mathrm{D}$ ratio with different viscous models

\section{Conclusions}

In this paper, a numerical simulation of the twin wedges impact considering dynamic equations of motion in two-phase flow is presented. The flow field around the wedges in two-phase flow is solved based on finite volume method with volume of fluid (VOF) scheme (in ANSYS Fluent and ANSYS CFX) and phase field scheme (in COMSOL Multiphysics) for tracking the free surface. The comparison between the present computations and experimental data shows that the present numerical simulation can predict time history of vertical velocity, vorticity, drag coefficient, pressure coefficient, total pressure, static pressure, dynamic pressure, hydrodynamic force and turbulence intensity magnitude in water impact with a good accuracy.

In this research, different moving computational meshes known as dynamic meshes in ANSYS Fluent, mesh motion in ANSYS CFX and moving mesh in COMSOL Multiphysics were utilized and it was concluded that the dynamic mesh of ANSYS Fluent is the best to simulate a water impact phenomenon. 
It was shown that the effects of turbulence and fluid compressibility during symmetric water impact are not so significant on wave patterns ANSYS CFX and COMSOL Multiphysics. Free surface patterns due to water impact are the same in ANSYS CFX and COMSOL Multiphysics for different viscous models but the significant differences were shown between patterns in ANSYS Fluent simulation.

ANSYS Fluent computed results had more precision to experimental data versus other two softwares. Using different viscous models result various computed values for all parameters but the $\mathrm{k}-\varepsilon$ turbulent viscous model had near computational results to experimental data. Finally, the best numerical results have been computed by Ansys Fluent software with the $\mathrm{k}-\varepsilon$ turbulent viscous model. Therefore, ANSYS Fluent and the $\mathrm{k}-\varepsilon$ turbulent viscous model are the best selections for simulation of water impact of twin 2D falling wedges.

\section{List of Symbols}

\begin{tabular}{|c|c|}
\hline$\alpha$ & $\begin{array}{l}\text { Angular acceleration of rigid body about } \\
\text { its gravity center }\left[\mathrm{rad} . \mathrm{s}^{-2}\right]\end{array}$ \\
\hline$\mu$ & Dynamic viscosity $\left[\mathrm{kg} \cdot \mathrm{s}^{-1} \cdot \mathrm{m}^{-1}\right]$ \\
\hline$\mu_{t}$ & Turbulent viscosity $\left[\mathrm{m}^{2} \cdot \mathrm{s}^{-1}\right]$ \\
\hline$\rho$ & Density $\left[\mathrm{kg} \cdot \mathrm{m}^{-3}\right]$ \\
\hline$\varphi$ & Volume fraction [non-dimensional] \\
\hline$D$ & Altitude of triangle $[\mathrm{m}]$ \\
\hline$F$ & Any external forces $\left[\mathrm{kg} \cdot \mathrm{m} . \mathrm{s}^{-2}\right]$ \\
\hline$\vec{F}$ & Hydrodynamics force $\left[\mathrm{kg} \cdot \mathrm{m} . \mathrm{s}^{-2}\right]$ \\
\hline$g$ & Gravity Acceleration $\left[\mathrm{m} . \mathrm{s}^{-2}\right]$ \\
\hline$I$ & Mass moment of inertia $\left[\mathrm{kg} \cdot \mathrm{m}^{-2}\right]$ \\
\hline$m$ & Mass $[\mathrm{kg}]$ \\
\hline$M$ & Moment vectors $\left[\mathrm{kg} \cdot \mathrm{m}^{2} \cdot \mathrm{s}^{-2}\right]$ \\
\hline$P$ & Pressure $\left[\mathrm{kg} \cdot \mathrm{m}^{-1} \cdot \mathrm{s}^{-2}\right]$ \\
\hline$t$ & Time $[\mathrm{s}]$ \\
\hline$u$ & Fluid velocity $\left[\mathrm{m} . \mathrm{s}^{-1}\right]$ \\
\hline$V$ & $\begin{array}{l}\text { Translational velocity of the center of } \\
\text { gravity }\left[\mathrm{m} \cdot \mathrm{s}^{-1}\right]\end{array}$ \\
\hline$x$ & Dimension [m] \\
\hline$Z$ & $\begin{array}{l}\text { Maximum height of water from initial } \\
\text { flat free surface }[\mathrm{m}]\end{array}$ \\
\hline
\end{tabular}

\section{References}

1- Xu, G.D., Duan, W.Y., and Wu, G.X., (2008), Numerical simulation of oblique water entry of an asymmetrical wedge, J. Ocean Engineering, Vol.35, p.1597-1603, [DOI: 10.1016/j.oceaneng.2008.08.002]. 2- Von Karman, T., (1929), The impact of seaplane floats during landing, NACA TN 321, Washington, DC.

3- Wagner, H., (1932), The phenomena of impact and planing on water. National Advisory Committee for Aeronautics, Translation, 1366, Washington, DC ZAMM. J. App. Math. Mech. Vol.12(4), p.193-215.
4- Shademani R. and Ghadimi, P., (2017), Asymmetric water entry of twin wedges with different deadrises, heel angles, and wedge separations using finite element based finite volume method and VOF, Journal of Applied Fluid Mechanics, Vol.10(1), p.353-368, [DOI: 10.18869/acadpub.jafm.73.238.26185. 353].

5- Ghazizade-Ahsaee, H. and Nikseresht, A.H., (2013), Numerical Simulation of Two Dimensional Dynamic Motion of the Symmetric Water Impact of a Wedge, International journal of maritime technology, Vol.1(1), p.11-22.

6- Armand, J.L. and Cointe, R., (1987), Hydrodynamic impact analysis of a circular cylinder, $5^{\text {th }}$ International Offshore Mechanics and Arctic Engineering. Tokyo, p.609-634.

7- Greenhow, M. (1987), Wedge entry into initially calm water, J. Applied Ocean Research. Vol.9, p.214233, [DOI: 10.1016/0141-1187(87)90003-4].

8- Farsi, M. and Ghadimi, P., (2015), Simulation of 2D symmetry and asymmetry wedge water entry by smoothed particle hydrodynamics method, J Braz. Soc. Mech. Sci. Eng. Vol.37(3), p.821-835, [DOI: 10.1007/s40430-014-0212-5].

9- Farsi, M. and Ghadimi, P., (2016), Effect of flat deck on catamaran water entry through smoothed particle hydrodynamics, In Proceedings of the Institution of Mechanical Engineers, Part M: Journal of Engineering for the Maritime Environment, Vol.230(2), p.267-280, [DOI: 10.1177/1475090214563960].

10- Yamada, Y., Takami, T. and Oka, M., (2012), Numerical study on the slamming impact of wedge shaped obstacles considering fluidstructure interaction (FSI), In Proceedings of the International Offshore and Polar Engineering Conference.

11- Luo, H., Wang, H. and Soares, C.G., (2012), Numerical and experimental study of hydrodynamic impact and elastic response of one free-drop wedge with stiffened panels, Ocean Eng. Vol.40, p.1-14, [DOI: 10.1016/j.oceaneng.2011.11.004].

12- Ghadimi, P., Saadatkhah, A. and Dashtimanesh, A. (2011), Analytical solution of wedge water entry by using Schwartz-Christoffel conformal mapping, Int. J. Model. Sim. Sci. Compu. Vol.2(3), p.337-354, [DOI: 10.1142/S1793962311000487].

13- Shah, S.A., Orifici, A.C. and Watmuff, J.H., (2015), Water impact of rigid wedges in twodimensional fluid flow, Journal of Applied Fluid Mechanics Vol.8(2), p.329-338, [DOI: 10.18869/acadpub.jafm.67.221.22693].

14- Panahi, R., (2012), Simulation of water-entry and water-exit problems using a moving mesh algorithm, J. of Theoretical and Applied Mechanics, Vol.42, p.79-92, [DOI: 10.2478/v10254-012-0010-3].

15- Panciroli, R., (2013), Water entry of flexible wedges: Some issues on the FSI phenomena, App. Ocean Res, Vol.39, p.72-74, [DOI: 10.1016/j.apor.2012.10.010]. 
16- Piro, D.J. and Maki K., (2013), Hydroelastic analysis of bodies that enter and exit water, J. Fluids and Structures, Vol.37, p.134-150, [DOI: 10.1016/j.jfluidstructs.2012.09.006].

17- Zhao, R. and Faltinsen, O.M., (1993), Water entry of two-dimensional bodies, J. Fluid Mechanics, Vol.246, p.593-612,

[DOI:

10.1017/S002211209300028X].

18- Booki, K. and Yung, S.S., (2003), An efficient numerical method for the solution of two-dimensional hydrodynamic impact problems, $13^{\text {th }}$ International Offshore and Polar Engineering Conference. Honolulu, Hawaii, USA, p.25-30.

19- Zhao, R., Faltinsen, O.M. and Aarsnes, J., (1996), Water entry of arbitrary two-dimensional sections with and without flow separation, $21^{\text {st }}$ Symposium on Naval Hydrodynamics, Trondheim, Norway. National Academy Press, Washington DC., p.408-423. 